\title{
SECOND REPORT ON THE IDENTIFICATION OF THE MENINGOCOCCUS IN THE NASO-PHARYNX, WITH SPECIAL REFERENCE TO SEROLOGICAL REACTIONS 1 .
}

\author{
By FRED. GRIFFITH, M.B.
}

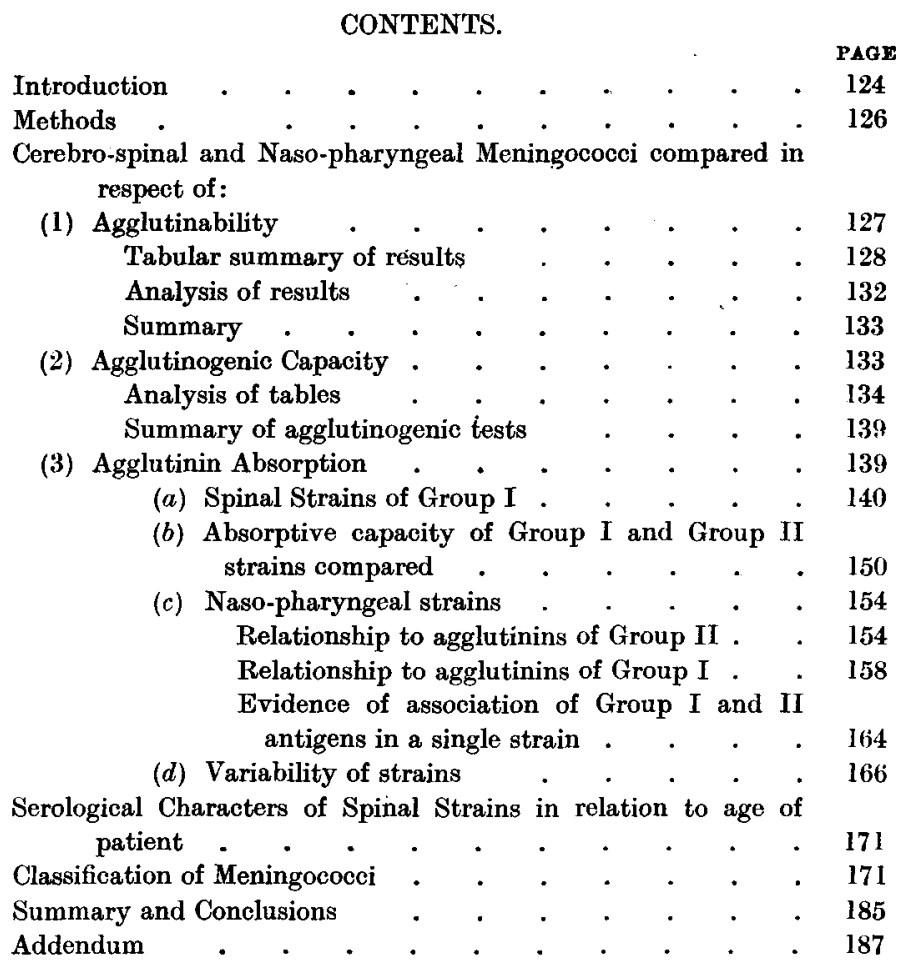

\section{INTRODUCTION.}

In the course of an inquiry initiated at the beginning of March, 1915, into the distribution of the meningococcus among the general population,

1 Reprinted from Reports to the Local Government Board on Public Health and Medical Subjects, n.s. No. 114 (1917), by permission of His Majesty's Stationery Office. 
Dr Eastwood and I had found a considerable percentage of Gramnegative cocci, indistinguishable by full cultural tests from spinal meningococci, in the naso-pharynx of out-patients attending at St Bartholomew's Hospital. These non-contact naso-pharyngeal strains were subjected by me to serological tests; and in a preliminary report ${ }^{1}$, issued in May, 1916, it was stated that they could not be excluded from the meningococcus species on the results of the agglutination reactions. The conclusion arrived at was, in effect, that cultural and fermentation tests were sufficient for the identification of the meningococcus in the naso-pharynx. Questions of differentiation by serological methods between strains of meningococci, whether spinal or naso-pharyngeal in origin, were raised, but no final decision was made.

To summarise briefly the main features of the previous report, the evidence obtained indicated that differences in antigenic capacity afforded a basis for the division of meningococci into two fairly well-defined groups. Moreover, this serological grouping was correlated with differences in fermentative activity in the presence of maltose and glucose. As an explanatory hypothesis I suggested that differences in agglutinin production and fermentative activity are attributable to the complexity of the meningococcus antigen, which contains two components. These give rise in the animal body to two groups of agglutinins, and the differentiation into two fairly distinct serological races is due to the fact that the majority of meningococcus strains contain these components in unequal proportions, one being markedly in excess of the other. Within each group differences are to be found because the dominant type of antigen is liable to slight variations in structure; and sometimes there is no clear distinction between the one group and the other, because in a minority of strains there is no marked preponderance of the one antigen component over the other.

The work has been continued in the hope that further light may be thrown upon this differentiation of meningococci into serological races, with particular reference to the biological relationship between cerebrospinal strains and those naso-pharyngeal strains which have been found to be of common occurrence amongst persons not associated with cases of cerebro-spinal fever. The pharyngeal strains investigated are 89 in number, including three strains of Gram-negative cocci which were distinguishable from meningococci by their pigment formation, and were used as controls. Of the 86 strains, all culturally identical with meningococci, 28 were studied in my previous report, and have been submitted

\footnotetext{
1 Reprinted in Journ. of Hygiene, xv. 446.
} 
to further investigation. The new strains, like those previously reported upon, have all been obtained from persons not known to have been associated in any way with cases of meningitis. The cerebro-spinal strains investigated are 66 in number, including 32 which were not mentioned in my last report.

In connection with the epidemic prevalence of cerebro-spinal fever, which occurred from February to May, 1915, and during approximately the same period but with a lower incidence in 1916, it may be of interest to record the periods in which the strains of meningococci were obtained. The spinal strains were derived from cases of meningitis occurring during the following periods: Cases 1-39, from March 23, 1915, to December 23, 1915 ; 40-66, from January 3, 1916, to September 14, 1916. The pharyngeal strains were obtained in three series from the out-patients at St Bartholomew's Hospital; 1-46, from March 29, 1915, to July 22, 1915 ; 47-56, from January 10, 1916, to January 24, 1916; 57-89, from April 6, 1916, to June 5, 1916.

I wish to express my indebtedness to Dr Eastwood for generous help in the preparation of this report, and to Dr Scott for much helpful criticism.

\section{METHODS.}

The usual methods of performing the macroscopic agglutination test described in my previous report have with some slight exceptions been adhered to. At first the suspensions used contained $4 \mathrm{mg}$. of moist cocci per c.c., but latterly suspensions of only $2 \mathrm{mg}$. per c.c. were preferred, as giving a sharper end-point.

All agglutinating sera were monovalent, and were prepared by inoculating rabbits intravenously with living cultures grown on glucose agar. Living culture taken from the medium immediately before inoculation appears to be less toxic than killed culture. The final readings of the agglutination tests were made after 24 hours in the incubator at $55^{\circ} \mathrm{C}$, and a further 12 hours in the ice-chest or at room temperature. For absorption tests the agglutinating sera have been used in dilutions of $1: 50$ and $1: 100$. Heated and unheated cultures have been used, both in small and in large amounts. Information on these points is given in the heading of each table. 


\section{CEREBRO-SPINAL AND NASO-PHARYNGEAL MENINGOCOCCI COMPARED IN RESPECT OF:}

\section{(1) AgGlutinability.}

The agglutination tests upon spinal and pharyngeal meningococci with monovalent meningococcus sera have been summarised for the purposes of comparison in Tables I and II. So far as possible the experimental conditions in the two series have been identical.

In interpreting the results of agglutination tests upon meningococci it is necessary to bear in mind the varying agglutinability of different suspensions of the same strain prepared at different times. The causes underlying this variability are not always the same, and in some instances there is evidence of an alteration, occurring during subcultivation, in the constitution of the culture from which the suspension was prepared. In other cases the failure to form clumps appears to be a temporary phase, and it is therefore impossible to assert, when the result with a particular serum is negative, that the response to that serum will invariably be the same. With the object of eliminating disturbing factors, so far as possible, many of the agglutination tests from which my tables have been prepared have been frequently repeated; where the results have differed, the highest titre has been recorded.

As regards the method adopted, the culture suspensions, after being heated to $65^{\circ} \mathrm{C}$. for $\frac{1}{2}$ to 1 hour, were diluted with 0.5 per cent. carbolic salt solution to a uniform density of $2 \mathrm{mg}$. per c.c. and were stored for several weeks before being used. The end-point chosen for comparative work is that dilution of serum in which the cocci have deposited, leaving the supernatant fluid clear or with very slight opalescence when examined in a good oblique light.

The figures in the tables represent the numerical value of the highest dilution in which the end-point was reached, the maximum recorded in the table being $1: 1000$. The titres of the six sera used were approximately equal, ranging from $1: 800$ to $1: 1600$ with different suspensions of each homologous strain. The symbols \pm and - indicate respectively an incomplete and a negative result at $1: 100$; tr. indicates slight agglutination, the supernatant fluid remaining turbid.

The six monovalent agglutinating sera were prepared with strains which had been grown from the cerebro-spinal fluid of cases of meningitis occurring during the 1915 period of prevalence of cerebro-spinal fever: they were chosen because they agglutinated between them most of the spinal strains. With the exception of M 34 none of the heated sus- 


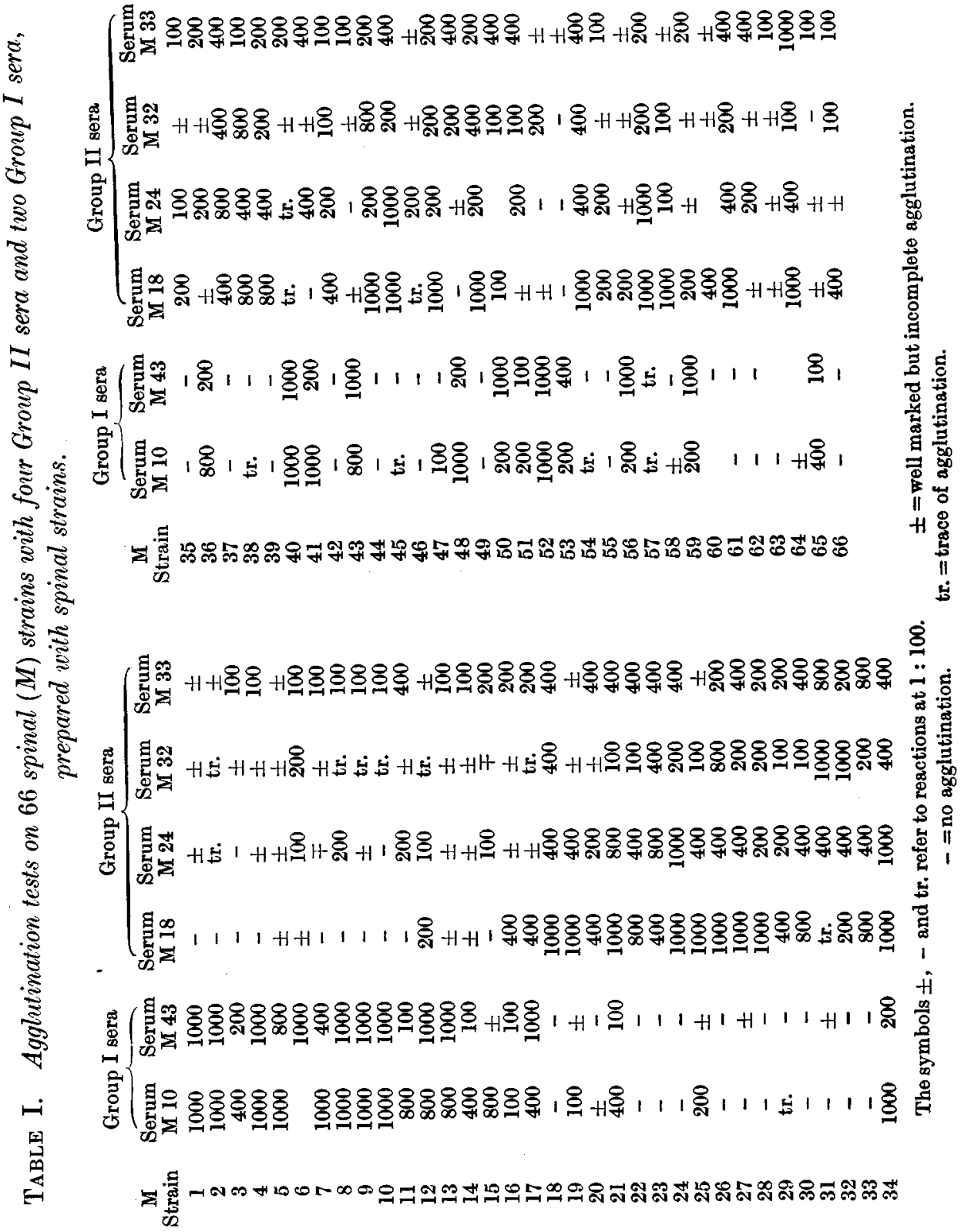




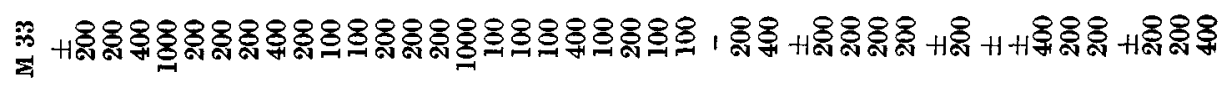

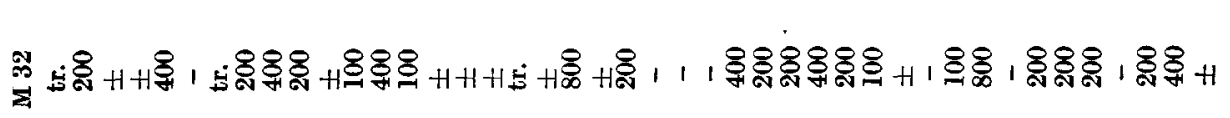

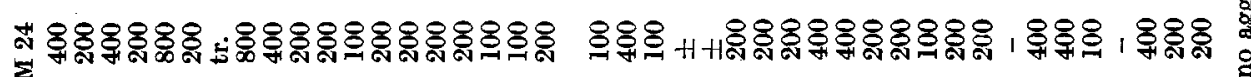

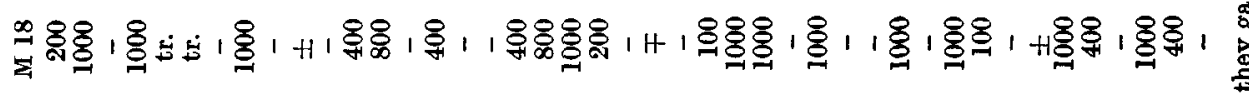

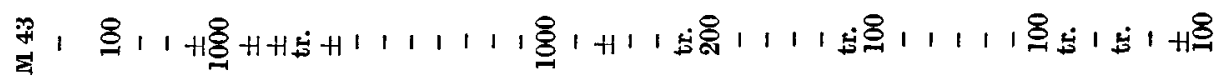

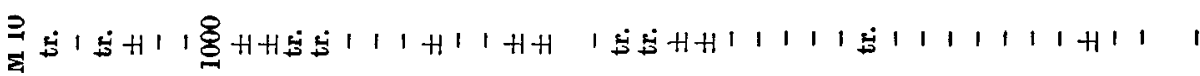

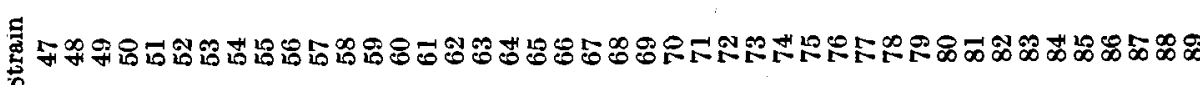

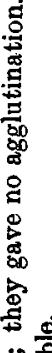
ثै

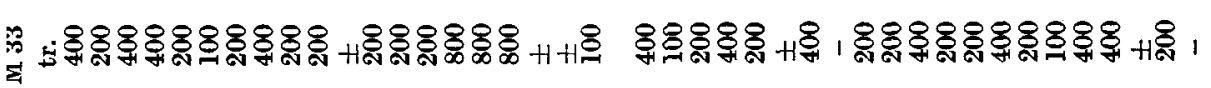

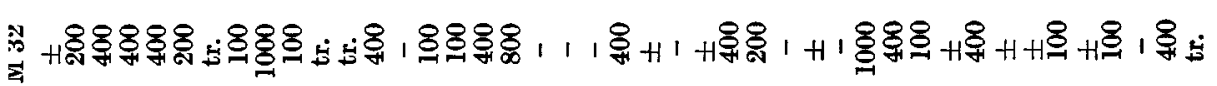
票:

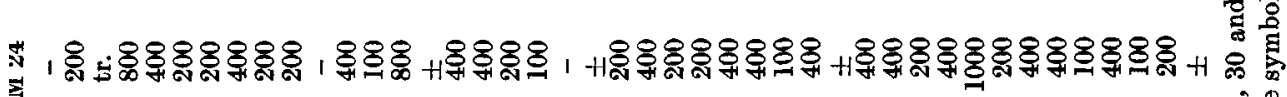

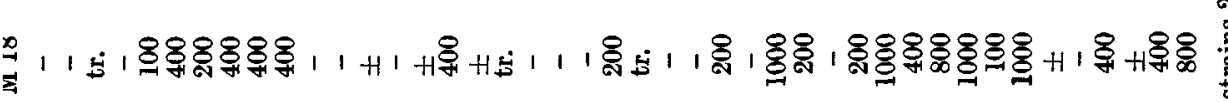
สิ

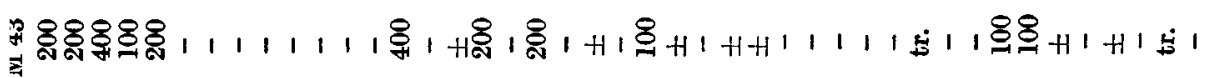

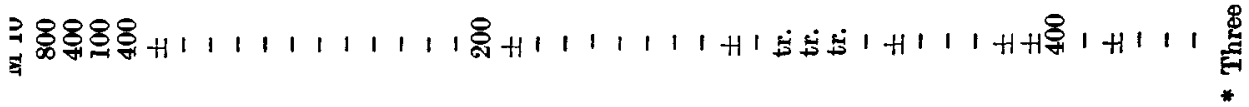

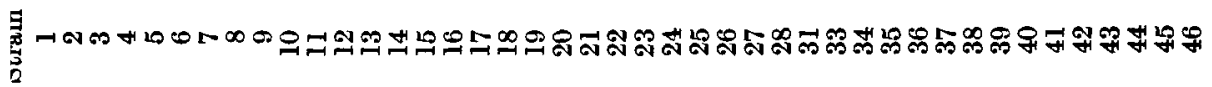
9-2 
pensions of the spinal or pharyngeal strains was agglutinated in $1: 50$ by normal rabbit serum.

Table I summarises the results with the spinal strains; the first 34 strains are arranged as in the previous report to show the grouping; the remaining strains are in the serial order in which they were obtained.

On examination of Table $I$ it will be seen that if the sera M 18 and M 24, which I call Group II, and M 10 and M 43, which I call Group I, are taken as standards, the spinal strains can be divided into two moderately well defined groups, excluding certain strains which may be classed as intermediate or indeterminate. Amongst the strains which appear to be definitely grouped are two, M 32 and M 33, which are agglutinated sufficiently well by M 18 and M 24 sera to be considered as belonging to the same group as the strains $M 18$ and M 24, and to a different group from M 10 and M 43 . But the sera produced with M 32 and $M 33$ invalidate the grouping, since they on the one hand agglutinate strains not affected by M 18 and M 24 sera, and on the other hand leave unaffected strains which these same two sera agglutinated.

It is clear, therefore, that the strains M 18, M 24, M 32 and M 33, which appear to belong to the same group, though closely inter-related as regards agglutinin production and agglutinability, are not identical with each other in either respect.

A further obstacle to the division of meningococci into two or more well-defined groups is the fact that there are strains either relatively inagglutinable towards the group sera or agglutinated equally by sera of both groups.

To sum up the position as regards agglutinability, the spinal meningococci can be separated into two main groups by means of selected sera, but such division cannot be strictly maintained if sera made from unselected strains are used, since strains grouped in a particular fashion by one set of sera do not necessarily behave uniformly in relation to a different set of sera. This division into two groups must therefore be admitted to be imperfect and somewhat artificial, since it depends on the arbitrary selection of particular sera and the exclusion of other sera. Nevertheless, when these limitations are recognised, a rough division into two main groups is of great importance to a correct appreciation of the inter-relationship between strains of meningococci.

The question of grouping strains may be looked at from another point of view which indicates the principle employed in selection. Every serum which exercises a definite selective action upon strains belonging to one or other of the two groups may be considered to 
contain agglutinins with special affinities for that particular group. Reviewing the method of classification used in my previous report, one finds that M 1 to M 17 were classed as Group I strains and M 18 to M 34 as Group II strains, on the ground of simple agglutinability with particular sera. From the above considerations, this may be more correctly expressed by saying that this grouping is based on a selective response to particular agglutinins, viz. a response to the predominant agglutinins produced by the antigens of $M 10$ and M 43 in the case of Group I and a response to the agglutinins produced by the antigens of $M 18, M 24$, M 32, M 33 in the case of Group II. In other words, agglutinogenic capacity would be a more scientifically accurate basis for classification, as it would provide identification of the antigens producing the special agglutinins. Agglutinability is too variable a property to be strictly reliable. It is, however, a useful guide to identification inasmuch as it effects a rough demarcation of strains into two groups. I have therefore continued to refer to particular strains as belonging to Group I or Group II when there is sufficient evidence of the predominance of one or other of the two group antigens.

Turning now to Table II, the next step in the analysis of these tables is to compare the agglutinability of spinal and pharyngeal strains in relation to the agglutinins of the above-mentioned six sera. This table, read in conjunction with Table I, shows that although an exact serological classification of meningococci into groups cannot, as shown in the previous discussion, be made upon the results of simple agglutination tests alone, important evidence of relationship is obtained which can be correctly interpreted by subsequent investigation of agglutinogenic and absorptive capacities. It will facilitate comparison of the two series of strains in respect of agglutinability if the tables are summarised in the following way. I have taken a titre which is sufficiently high to be regarded as of definite serological significance, and have ascertained the total number of strains in the two series attaining or surpassing this titre in respect of each serum. Since each of the six sera has a titre ranging from $1: 800$ to $1: 1600$ with different suspensions of the homologous strain, a complete agglutination result in a dilution of $1: 400$ may be taken to constitute important evidence of relationship. The results are summarised in the following table, which gives under the heading of each serum the percentage of spinal and pharyngeal strains agglutinated completely in a dilution of $1: 400$ or over. 
TABLE III.

Summary of Tables $I$ and $I I$, giving the percentages of spinal and pharyngeal strains agglutinated to $1: 400$ by each serum.

\begin{tabular}{|c|c|c|c|c|c|c|}
\hline Total strains & $\begin{array}{c}\text { M } 18 \\
\text { Serum }\end{array}$ & $\begin{array}{c}\text { M 24 } \\
\text { Serum }\end{array}$ & $\begin{array}{c}\text { M } 32 \\
\text { Serum }\end{array}$ & $\begin{array}{r}\text { M } 33 \\
\text { Serum }\end{array}$ & $\begin{array}{r}\text { M } 10 \\
\text { Serum }\end{array}$ & $\begin{array}{r}\text { M 43 } \\
\text { Serum }\end{array}$ \\
\hline 66 spinal . & $47 \%$ & $35 \%$ & $17 \%$ & $33 \%$ & $41 \%$ & $30 \%$ \\
\hline 86 pharyngeal & $37 \%$ & $34 \%$ & $24 \%$ & $25 \%$ & $6 \%$ & $5 \%$ \\
\hline
\end{tabular}

Comparing one series with the other as regards the total strains agglutinated by one or more of the six sera, it is found that 94 per cent. of the 66 spinal strains were agglutinated to $1: 400$ or over, and 72 per cent. of the 86 pharyngeal strains reacted to a similar extent.

It will be seen from Table III that the relative proportions of spinal and pharyngeal strains agglutinated up to $1: 400$ by the Group II sera do not differ materially. The agglutinins of M 18 and M 33 sera find among the spinal strains more combining affinities than among the pharyngeal, but the reverse is the case with M 32 serum, and M 24 serum influences spinal and pharyngeal strains in equal numbers.

In striking contrast to the above, the Group I agglutinins contained in $M 10$ and $M 43$ sera find related antigens 6-7 times more frequently among the spinal than among the pharyngeal strains.

Two alternative explanations may be suggested to account for this difference in reaction between naso-pharyngeal and cerebro-spinal strains in the presence of a Group I serum:

(1) Group I antigen is a rare component of the pharyngeal meningococcus of the non-contact, while it is represented as commonly as Group II antigen in strains of spinal meningococci. Thus, if the proportions found in this investigation reflect the general distribution of the two groups, both in meninges and naso-pharynx, it may be inferred that the meningococcus of Group I more frequently invades the meninges from the naso-pharynx than the meningococcus of Group II.

(2) The antigen of Group I in the pharyngeal meningococcus, though not revealed by the two Group I sera used, might be shown to have combining affinities for agglutinins produced by other spinal strains containing Group I antigen.

Some evidence in regard to this second hypothesis is furnished by agglutination tests with sera of Group I prepared with M 15, M 16, and $M 17$.

M 17 serum, titre $1: 800$ to $1: 1600$, was found to agglutinate completely NP 4 and NP 5 up to $1: 800 ;$ NP $3,17,53,65,70,71$, up to $1: 400 ; \mathrm{NP} 67$ and 86 up to $1: 200$. 
M 15 serum, titre $1: 400$, agglutinated completely in $1: 100$, NP 19 , $21,24,44,52,56,60$, and 70 .

M 16 serum, titre $1: 800$ to $1: 1600$, agglutinated NP 2 to $1: 800$, NP 70 and 71 to $1: 400$, and NP 74 to $1: 200$.

A further point brought out by comparison of Tables I and II is that the number of spinal strains not agglutinated by any of the six spinal sera up to $1: 400$ was 4 ( 6 per cent.), while the corresponding number of pharyngeal strains was 24 (28 per cent.). This clearly constitutes a distinction of some importance between the spinal and the pharyngeal strains. But failure to attain an arbitrary standard of agglutination on the part of certain pharyngeal strains is no proof that they are specifically different from meningococci of proved pathogenicity, since on the same grounds a proportion of the latter would also be excluded from the meningococcus species.

It is possible that the spinal strains which were agglutinated weakly by the selected spinal sera have other serological features in common with the similarly reacting pharyngeal strains. The relationship of these strains to each other and to other spinal strains will be considered later in the light of the more precise knowledge of the combining qualities of antigens which can be gained from the production of agglutinating sera and from agglutinin absorption experiments.

The general result of the comparison of naso-pharyngeal strains with cerebro-spinal in respect of agglutinability may be summed up as follows:

(1) The agglutinins of Group II in the sera produced by M 18, M 24, M 32, and M 33 combine in almost equal proportions with spinal and pharyngeal strains.

In contrast, the agglutinins of Group I in the sera produced by M 10 and $M 43$ have more combining affinities with spinal strains than with pharyngeal.

(2) Strains which have little capacity for combining with the agglutinins of either Group I or Group II in the six spinal sera are found between four and five times more often in the pharyngeal series of meningococci than in the spinal.

\section{(2) Agglutinogenic Capacity.}

In the preceding section, which deals with simple agglutination tests, under identical conditions, on cerebro-spinal and naso-pharyngeal strains, six monovalent agglutinating sera prepared with spinal strains were employed. Two of these sera, M 10 and M 43, were found to exer- 
cise a selective action upon one group of strains, while the two sera, M 18 and M 24, influenced a second group which were not agglutinated by the first two sera. The strains M 10 and M 43 evidently possess antigenic capacities which differ from those of $M 18$ and $M 24$. The agglutinins which each of these four strains produces are capable of combining with similar antigens in other strains, but the reaction of agglutination resulting from such combination is not necessarily evidence that the antigens concerned are equally represented in the strain agglutinated and in the strain producing the agglutinin. For example, the strains M 32 and M 33 are agglutinated by the Group II sera M 18 and $M$ 24, but the sera which they produce are by no means identical either with the latter or with each other in their selective action upon the whole series of spinal meningococci (see Tables I and II). In my previous report a more marked illustration was given of the absence of correspondence between agglutinability and agglutinogenic capacity. Two strains, NP 10 and NP 11, were both agglutinated by the same Group II sera, and were almost identical in agglutinability. While the serum produced with NP 10 agglutinated exclusively the spinal strains of Group II, NP 11 serum agglutinated mainly the Group I spinal strains.

The above evidence indicates that agglutinogenic capacity sometimes brings to light affinities not demonstrable by simple agglutination between the antigens possessed by different strains. Further observations have been made with a view to ascertaining whether the complete antigenic capacities of the various strains are revealed by the tests of agglutinability with the six selected sera, the results of which are summarised in the first two tables. Certain pharyngeal and spinal strains were selected for the preparation of agglutinating sera. The results of tests with these sera on spinal and pharyngeal strains are set out in Tables IV, V, and VI. There is a difference in technique which must be noted in comparing these with the preceding tables. In the preceding tables the strength of the suspensions was $2 \mathrm{mg}$. per c.c., but in these it was $4 \mathrm{mg}$. per c.c. throughout, and this alteration approximately doubles the apparent agglutinating titre.

\section{Analysis of Table $1 \mathrm{~V}$.}

The sixteen naso-pharyngeal strains, NP 31-NP 46, represent the positive findings (except NP 32) from about 200 consecutive throat swabs. They form an unselected series which may be taken as an average sample of non-contact meningococci. NP 32 , included as a 
TABLE IV.

Agglutination tests on an unselected series of 16 naso-pharyngeal strains with a Group I spinal serum and a Group II spinal serum and with sera made from 8 naso-pharyngeal strains.

\begin{tabular}{|c|c|c|c|c|c|c|c|c|c|c|}
\hline Strain & $\begin{array}{c}\text { M } 23 \\
\text { Serum }\end{array}$ & $\begin{array}{c}\text { M } 9 \\
\text { Serum }\end{array}$ & $\begin{array}{l}\text { NP } 10 \\
\text { Serum }\end{array}$ & $\begin{array}{l}\text { NP 11 } \\
\text { Serum }\end{array}$ & $\begin{array}{l}\text { NP 36 } \\
\text { Serum }\end{array}$ & $\begin{array}{l}\text { NP } 39 \\
\text { Serum }\end{array}$ & $\begin{array}{l}\text { NP 40 } \\
\text { Serum }\end{array}$ & $\begin{array}{l}\text { NP 41 } \\
\text { Serum }\end{array}$ & $\begin{array}{l}\text { NP } 43 \\
\text { Serum }\end{array}$ & $\begin{array}{l}\text { NP } 44 \\
\text { Serum }\end{array}$ \\
\hline NP 31 & - & - & - & 200 & 400 & \pm & \pm & \pm & \pm & 400 \\
\hline $\mathrm{VP} 32^{*}$ & - & - & - & - & - & - & - & - & - & - \\
\hline NP 33 & 100 & \pm & \pm & 100 & 200 & - & - & 100 & - & \pm \\
\hline NP 34 & 400 & - & 100 & 200 & - & \pm & \pm & - & \pm & 400 \\
\hline NP 35 & 200 & - & 200 & \pm & - & \pm & - & - & - & \pm \\
\hline NP 37 & 200 & - & 200 & - & - & - & - & - & - & - \\
\hline NP 38 & 400 & - & 200 & 100 & - & \pm & - & - & \pm & 100 \\
\hline NP $36 \dagger$ & 200 & \pm & 100 & 1000 & 800 & 100 & 100 & 100 & 200 & 200 \\
\hline NP 39 & - & \pm & - & 100 & 100 & 400 & 200 & \pm & 100 & 800 \\
\hline NP 40 & - & 200 & - & 200 & \pm & 200 & 400 & \pm & 200 & 400 \\
\hline NP 41 & - & \pm & \pm & 1000 & 200 & - & 200 & 800 & 200 & \pm \\
\hline NP 42 & - & - & - & 800 & 200 & \pm & - & - & 100 & 200 \\
\hline NP 43 & - & 100 & \pm & 1000 & 200 & 200 & 200 & 400 & 400 & 800 \\
\hline NP 44 & - & - & \pm & 200 & - & 100 & 100 & \pm & 200 & 400 \\
\hline TP 45 & 1000 & - & 400 & 200 & 100 & 200 & \pm & \pm & \pm & 200 \\
\hline & - & - & - & - & - & - & - & - & $\rightarrow$ & 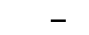 \\
\hline
\end{tabular}

* Pigmented Gram-negative coccus.

$\dagger$ NP 36 has been removed from its serial order to make clearer the tendency to grouping.

control, was a golden yellow pigmented culture of a gram-negative coccus with the fermentation reactions of the meningococcus.

Orientation tests were made with two spinal sera upon the pharyngeal suspensions, which were the same throughout, and the results are given in the second and third columns. M 9 serum contains agglutinins of Group I, and M 23 serum agglutinins of Group II. It will be seen from the table that seven of the pharyngeal strains are agglutinated by the Group II serum and two by the Group I, the remainder not responding to the action of either serum.

In the light of these results, certain of the pharyngeal strains were selected for the production of sera, preference being given to those which were not agglutinated to any marked degree by either of these two spinal sera ${ }^{1}$. The two sera made with NP 10 and NP 11, referred to above, were included for comparison.

The results of these tests, as shown in the table, are that, with the exception of NP 10 serum, none of the pharyngeal sera agglutinates

1 Later tests, however, showed that several were agglutinated by other spinal sera of Group II, M 18 and M 24. (See Table II.) 
the same collection of pharyngeal strains as the two standard spinal sera. NP 10 has almost the same selective action as M 23 serum (Group II). The agglutination results with the other pharyngeal sera appear at first sight irregular, but present the following features of significance:

(1) They generally fail to agglutinate those pharyngeal strains which were agglutinated by the standard Group II serum (M 23).

(2) They are fairly consistent in agglutinating the strains not affected by $M 23$ serum.

(3) They agglutinate NP 40 and NP 43, the only two strains in this series affected by the standard Group I serum (M 9).

(4) They therefore differ from Group II, as represented by M 23 antigen, and appear to resemble Group I, as represented by M 9 antigen.

In order to throw further light on the characters of these pharyngeal strains I have tested the sera prepared with them upon two series of spinal strains representative of Group I (Table V) and Group II (Table VI).

\section{TABLE V.}

Agglutination tests on spinal strains of Group I with sera prepared from six naso-pharyngeal strains, and from two spinal strains of relatively feeble absorptive capacity.

\begin{tabular}{|c|c|c|c|c|c|c|c|c|c|}
\hline Str & & $\underset{\text { Serum }}{\text { M } 16}$ & $\begin{array}{c}\text { M } 16 \\
\text { Serum }\end{array}$ & $\begin{array}{l}\text { NP } 39 \\
\text { Serum }\end{array}$ & $\begin{array}{l}\text { NP 40 } \\
\text { Serum }\end{array}$ & $\begin{array}{l}\text { NP 41 } \\
\text { Serum }\end{array}$ & $\begin{array}{l}\text { NP 43 } \\
\text { Serum }\end{array}$ & $\begin{array}{l}\text { NP } 44 \\
\text { Serum }\end{array}$ & $\begin{array}{c}\text { NP 36 } \\
\text { Serum }\end{array}$ \\
\hline M 1 & . & $\cdot \quad \pm$ & 800 & 400 & 200 & 200 & 200 & 400 & 200 \\
\hline M 2 & . & . 200 & 200 & 200 & 100 & 200 & \pm & 200 & 200 \\
\hline M 3 & . & . 100 & 200 & 200 & 200 & 200 & 100 & 400 & 200 \\
\hline M 4 & . & \pm & 200 & 400 & 200 & 200 & 200 & 400 & 200 \\
\hline M 5 & . & - $\quad \pm$ & 200 & 400 & 200 & 200 & 200 & 200 & 200 \\
\hline M 7 & . & \pm & 200 & 200 & 200 & 200 & 100 & 100 & 200 \\
\hline M 8 & . & . 100 & 200 & 400 & 200 & 200 & 200 & 400 & \pm \\
\hline M 9 & . & . 200 & 200 & 200 & 200 & 200 & 200 & 400 & 200 \\
\hline M 10 & . & \pm & 200 & 100 & 200 & 200 & 100 & 200 & 200 \\
\hline M 11 & . & 200 & 200 & 200 & 400 & 400 & 100 & 400 & 200 \\
\hline M 12 & . & $\cdot \quad \pm$ & - & 200 & 400 & 100 & 200 & 200 & 200 \\
\hline M 13 & . & . 100 & - & 200 & 100 & \pm & \pm & 400 & 200 \\
\hline M 14 & . & \pm & 100 & 100 & 100 & 400 & 100 & 200 & 200 \\
\hline M 15 & . & \pm & - & \pm & 200 & 800 & 100 & 200 & 200 \\
\hline M 16 & . & $* \pm$ & 100 & \pm & \pm & 400 & 100 & 200 & 100 \\
\hline M 17 & . & $\cdot \quad \pm$ & \pm & 200 & 200 & 100 & 100 & 400 & 400 \\
\hline M 36 & . & . 400 & \pm & 100 & 200 & 400 & 100 & 400 & 100 \\
\hline M 40 & . & \pm & \pm & 200 & 400 & 100 & 200 & 400 & 400 \\
\hline M 41 & . & 200 & 100 & 200 & 200 & 400 & 200 & 400 & 200 \\
\hline M 43 & & 200 & 100 & 100 & 100 & 200 & \pm & 400 & 200 \\
\hline M 46 & & \pm & 100 & & & & 200 & \pm & \pm \\
\hline
\end{tabular}




\section{F. GRIfFitiI}

TABLE VI.

Agglutination tests on spinal strains of Group II to compare with Table $V$.

\begin{tabular}{|c|c|c|c|c|c|c|c|c|}
\hline Strain & $\begin{array}{c}\text { M } 16 \\
\text { Serum }\end{array}$ & $\begin{array}{c}\text { M 46 } \\
\text { Serum }\end{array}$ & $\begin{array}{l}\text { NP } 39 \\
\text { Serum }\end{array}$ & $\begin{array}{l}\text { NP } 40 \\
\text { Serum }\end{array}$ & $\begin{array}{l}\text { NP 41 } \\
\text { Serum }\end{array}$ & $\begin{array}{l}\text { NP } 43 \\
\text { Serum }\end{array}$ & $\begin{array}{l}\text { NP } 44 \\
\text { Serum }\end{array}$ & $\begin{array}{l}\text { NP } 36 \\
\text { Serum }\end{array}$ \\
\hline M 18 & \pm & \pm & 200 & \pm & $t$ & \pm & 200 & - \\
\hline M 19. & \pm & - & \pm & - & \pm & \pm & \pm & - \\
\hline M 20 . & - & - & \pm & - & - & \pm & \pm & \\
\hline M 21 & 800 & 400 & 200 & - & 400 & \pm & 200 & 100 \\
\hline M 22. & - & \pm & 200 & 100 & 100 & 200 & 200 & 100 \\
\hline M 23 . & - & \pm & \pm & 100 & \pm & - & 100 & + \\
\hline M 24 & - $\quad \pm$ & \pm & \pm & \pm & - & - & \pm & - \\
\hline M 25 & . \pm & 100 & \pm & - & \pm & 100 & \pm & \pm \\
\hline M 26 . & - & \pm & 100 & 100 & \pm & \pm & 100 & 100 \\
\hline M 27 . & \pm & - & \pm & - & \pm & \pm & 100 & \\
\hline M 28 . & \pm & - & - & - & - & - & \pm & \\
\hline M 29. & \pm & \pm & \pm & - & \pm & \pm & 200 & \\
\hline M 30 & - & - & $\pm{ }^{\prime}$ & 100 & - & - & \pm & r \\
\hline M 31 . & $\cdot \quad \pm$ & - & \pm & - & \pm & - & \pm & - \\
\hline M 32 . & . $\quad \pm$ & - & - & \pm & - & - & \pm & \\
\hline M 33 . & 100 & \pm & \pm & \pm & - & & 200 & \pm \\
\hline M 34 . & \pm & \pm & & & 200 & & 100 & \pm \\
\hline M 35 . & - & \pm & \pm & - & \pm & - & \pm & \\
\hline M 37 & \pm & \pm & \pm & \pm & \pm & \pm & 200 & \\
\hline M 38 & - & \pm & \pm & 100 & \pm & - & 100 & \\
\hline M 39. & - & - & 100 & - & - & \pm & 100 & - \\
\hline M 42 . & \pm & - & \pm & - & - & - & \pm & \\
\hline M 44 . & \pm & \pm & \pm & \pm & . & 100 & \pm & \\
\hline M 45. & . 100 & 100 & 100 & \pm & \pm & 100 & 200 & \pm \\
\hline
\end{tabular}

These tables (V and VI) show the following results with the sera prepared from the six strains NP 36-44:

(a) Good agglutination with cerebro-spinal meningococci, though usually short of full titre.

(b) More uniform influence on Group I strains.

(c) Agglutination of some of the Group II strains to half full titre.

It will be observed that: $(a)$ shows the relationship of these strains to cerebro-spinal meningococci; $(b)$ confirms their antigenic relationship to Group I, already suggested by M 9 serum above; $(c)$ shows their relationship to Group II antigens, which was not brought out by M 23 serum, but had been indicated (Table II, p. 129) by agglutination tests with other Group II sera (M 18, etc.).

Tests of agglutinogenic capacity therefore show that some of these naso-pharyngeal strains, e.g. NP 44, possess both Group I and Group II antigens. As a parallel to this interesting fact, I call attention to the 
following details of tests with three spinal sera, two of which are included in Tables V and VI. In agglutinogenic capacity the strains M 16, M 46 and M 55, used to produce the sera, appear to have features in common with the above-mentioned pharyngeal strains.

M 16 was agglutinated to $1: 100$ with $M 8$ serum (Group I), and at first absorbed the homologous agglutinin well, but not completely. After prolonged subculture it retained its slight agglutinability towards Group I sera, and was also agglutinated by certain Group II sera, but exhibited no absorptive capacity for sera of either group. After repeated inoculations of living culture into a rabbit, a serum was obtained which agglutinated the homologous strain incompletely in from $1: 100$ to $1: 400$. Later the homologous strain became much more agglutinable, giving a complete reaction to the same serum in $1: 800$ to $1: 1600$. The results of the agglutination tests show it to be an indifferent serum of low multivalency, related slightly to both groups. M 46 was obtained from basal meningitis in an infant, and in its relative inagglutinability resembled certain pharyngeal strains previously mentioned. Although M 46 was agglutinated a little by M 24 serum (Group II) and not by the two Group I sera, its agglutinogenic capacity reveals a closer relationship to the spinal strains agglutinated by Group I sera.

M 55 was another cerebro-spinal strain which, like the above two, could not be identified with either of the two groups which form the majority; it was obtained from a case of post-basal meningitis in a child aged eight months. It was agglutinated slightly by Group II sera. A serum was prepared from it and tests were made upon the spinal strains. The agglutination results, which are not given in the table, are as follows. The homologous strain was agglutinated completely in a dilution of $1: 800$, and $M 31$ to $1: 400$; none of the other spinal strains tested, whether of Group I or Group II, was agglutinated higher than $1: 100$. Brief reference may be made to the reactions of two of the remaining pharyngeal strains.

NP 31 had poor antigenic qualities and produced a serum with no higher titre than 1:200 for the homologous culture. This serum agglutinated only two of the spinal strains of Group II up to $1: 200$ and none of the Group I strains.

NP 46 culture was tested with a large number of spinal and pharyngeal sera, and seemed to have no combining affinities until it was tried with $M 18$ serum (titre about $1: 1600$ ) which agglutinated it completely up to $1: 800$. Its agglutinogenic capacity was not tested. 


\section{Summary of Agglutinogenic tests.}

The following inferences are to be drawn from the above results.

(1) Agglutinability does not invariably correspond with agglutinogenic capacity.

(2) The production of an agglutinating serum, i.e. the demonstration of agglutinogenic capacity, confirms the evidence of specific relationship between spinal and pharyngeal strains based on the agglutination tests with standard meningococcus sera.

(3) In both the cerebro-spinal and the naso-pharyngeal series, strains occur in which there is no marked predominance of one group antigen over the other.

(4) Compared with the standard spinal strains these pharyngeal strains with the characters described above may be summed up as being less well defined in relation to the two main groups both in agglutinability and in agglutinogenic capacity. In this respect there is a close analogy between them and the anomalous spinal strains, M 16, M 46 and M 55 .

\section{(3) Agglutinin Absorption.}

The preceding experiments on agglutinability and agglutinogenic capacity have shown that cerebro-spinal and naso-pharyngeal meningococci possess antigenic substances common to both classes, and that the serological differences which can be demonstrated between spinal and pharyngeal strains are not greater either qualitatively or quantitatively than the differences between individual spinal strains.

It is recognised that an antigen may be the common constituent of related organisms which have specifically distinct pathogenic properties, and that agglutinability in itself is not conclusive evidence of identity. On the same grounds, but to a less degree, the evidence supplied by agglutinogenic capacity may not always be conclusive. A strain of gonococci, for example, may produce a serum which agglutinates some strains of meningococci. The final criterion of serological identity is the absorption of agglutinin. This test provides more precise information as to the combination of agglutinin and antigen than the simple agglutination test alone, and it defines more clearly than the agglutinogenic test the degree of relationship between the antigens of different strains.

The absorption tests have been carried out on the following plan. In the first place the relationship between the different spinal strains has been worked out, and several varieties of antigens and agglutinins 
have been defined in each of the two main groups. The results have then been applied to the identification of such combining affinities in the naso-pharyngeal strains and sera as are similar to the affinities exhibited by the antigens and agglutinins of the spinal strains.

A uniform method of absorption has not been adopted: the quantities and condition, i.e. heated or unheated, of the culture employed for absorption, and the dilutions of the absorbed serum have been varied and will be noted under each series of experiments. The experiments have been arranged in two series following the rough classification into two groups indicated by agglutination, on the assumption that there are two primary antigenic substances in the meningococcus and that the agglutinins produced by one substance or its variations cannot combine with the other.

\section{Agglutinin absorption with spinal strains of Group $I$.}

The method adopted was to bring together equal parts of a 1 in 25 dilution of serum and a heated suspension containing $4 \mathrm{mg}$. of cocci per cubic centimetre. After absorption, which was generally allowed to take place at room temperature, the serum was titrated and tested in dilutions of 1 in 100 up to the full titre on the strain with which the serum had been prepared (referred to as homologous). Specific absorption of agglutinin was considered to have taken place when the agglutinating power of the absorbed serum was definitely reduced for the homologous strain. The standard of reduction was that produced by the homologous strain itself under the same conditions.

The sera used in this series were those which contained mainly the agglutinins of Group I. For absorption, 21 strains all agglutinated by these sera were selected from the first 46 spinal strains. To these M 46 was added, because, though not agglutinated by these sera, it was shown to produce agglutinins for Group I strains. The number of strains used was limited in the first instance to these 22 , in order that the test with each serum might be completed on a single occasion, and that the conditions of each experiment should be identical for all the strains concerned.

The absorption tables are arranged as follows. In the first column are the strains used for absorbing the serum. The succeeding columns show the results of testing, in the dilutions given at the head of each column, the agglutinating action of the serum upon a test suspension, generally that of the strain producing the serum. The first test is with the unabsorbed serum; the rest show how this initial titre is affected 
by the treatment with éach of the strains used for absorbing. In Table VII an absorption experiment with M 10 serum is given in full. It consists of two parts, showing the effect of two successive additions of culture. As will be seen, certain of the 22 strains removed varying amounts of the agglutinin which acts upon $M 10$, while others left this agglutinin unaffected.

The result with M 6 shown in Table VII is exceptional. At the time when the culture for absorption was made this strain had lost its agglutinability and absorbing capacity, which were originally the same as the other strains in the first ten. On returning to an older subculture and retesting, the original absorbing capacity was exhibited.

\section{TABle VII.}

$M 10$ serum absorbed with 22 spinal strains. Absorbed and unabsorbed serum titrated and tested upon the same suspension of the homologous strain.

Method. First absorption: equal parts of 1:25 dilution and suspensions containing $4 \mathrm{mg}$. of heated culture per c.c. Second absorption: each suspension again added to the absorbed serum now in $1: 50$ dilution.

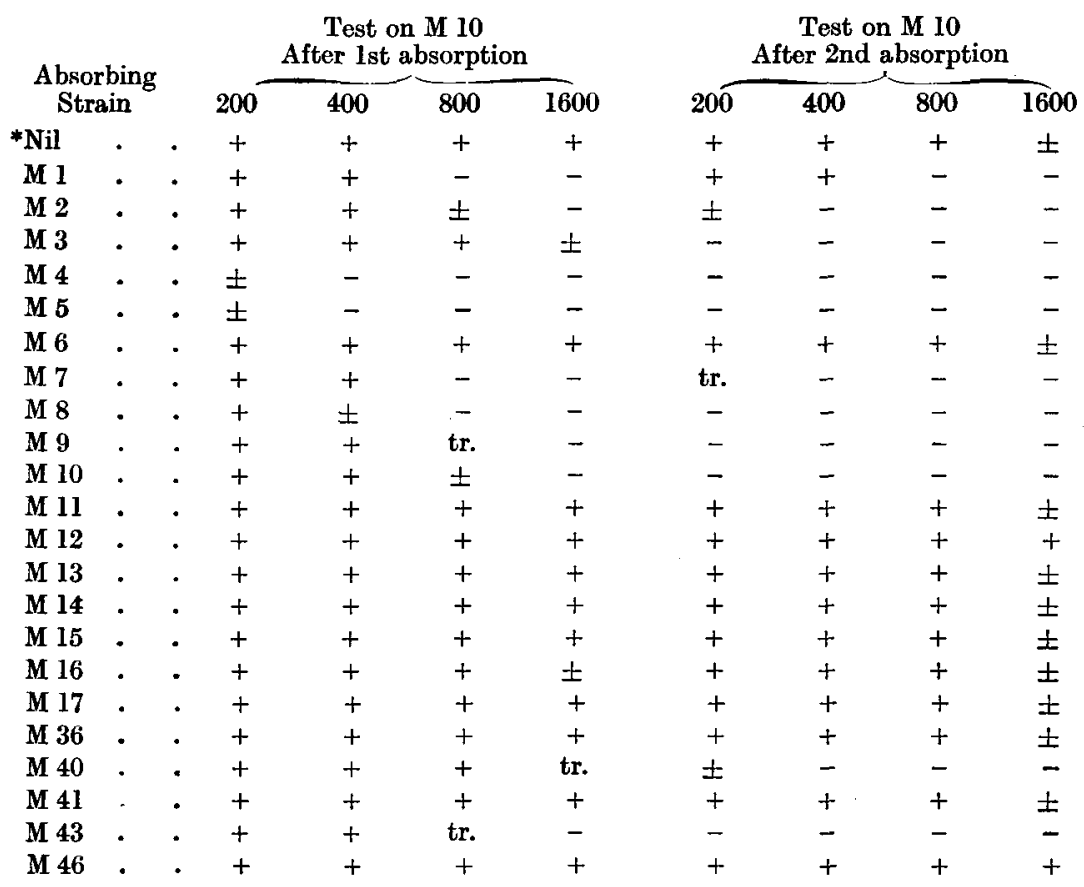

* Nil signifies that the test on M 10 suspension is with the control portion of M 10 serum treated like the others except that no culture was added.

In this and succeeding tables $+=$ complete agglutination, $\pm=$ incomplete agglutina. tion, $-=$ no agglutination, tr. = trace of agglutination. 
Sera were prepared with some of the strains which absorbed and with others which failed to absorb, and have been used to test in a similar manner the absorbing capacity of the whole series of 22 . The extent to which the agglutinin was removed varied with different sera, but in general the ease with which the agglutinating power of a serum with a titre of over 1:1000 was almost completely annulled by small amounts of culture was characteristic of sera of this group.

For the sake of brevity $I$ have not reproduced in detail the tables recording the tests with the other sera, but have summarised the results. In the following scheme I have taken the 22 strains, and shown that they differ in range of absorptive capacity (indicated by a thick horizontal line) when tested against six sera.

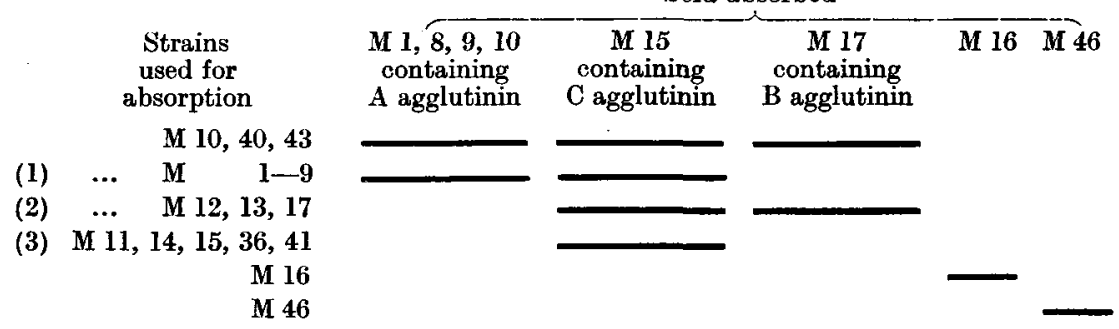

$\begin{array}{lll}\text { (1) Sub-group A. } & \text { (2) Sub-group B. } & \text { (3) Sub-group C. }\end{array}$

Strains 11, 14, 15, 36, and 41 remove only the agglutinin from M 15 serum, which must therefore contain an agglutinin with a special combining affinity for a particular antigen in that group of strains. This agglutinin may be designated $\mathrm{C}$.

Strains 12, 13, and 17 remove not only M 15 agglutinin, but, unlike 11-41, also M 17 agglutinin. This group must therefore contain an additional antigen with a combining affinity for a different agglutinin in $\mathrm{M} 17$ serum. The latter may be designated $\mathrm{B}$.

Strains 1-9 agree with 11-41 in removing $C$ agglutinin and in failure to remove $B$ agglutinin, but differ from both $11-41$ and 12-17 in removing the agglutinin from the sera $M 1,8,9$, and 10 , which were not affected by either of the two last mentioned groups of strains. These sera, M 1-10, must therefore contain an agglutinin, not present in sera M 15 or M 17, which may be designated $A$.

Strains 10, 40, and 43 remove both $A, B$, and C.

Strains 16 and 46 remove neither $\mathrm{A}, \mathrm{B}$, nor $\mathrm{C}$, but only the agglutinin from their own sera. They are put in Group I because they agglutinate Group I strains better than Group II (see pp. 136-7). 
The special characters of the various Group I sera used in the above summary require some annotation.

M 1 serum had a titre of $1: 1600$ and was prepared after the strain had been sub-cultivated for nearly a year. A definite distinction between the strains respectively absorbing and non-absorbing was brought out by agglutination tests alone with this serum, which was not the case with the other sera of this sub-group A. Absorption was well marked, the titre being reduced from $1: 1600$ to less than $1: 100$, and the same strains which absorbed the homologous agglutinin also absorbed from M 1 serum the agglutinin which acted on M 10 and M 43 .

M 8 serum had a titre of $1: 800$. While there was not brought out by simple agglutination the same differentiation as above between the absorbing and non-absorbing strains, the differences in absorptive capacity were well marked, not the least reduction being effected by the latter, while a large reduction was produced by the former.

M 9 serum, with a titre of $1: 800$, was not so readily absorbed as the two preceding sera. M 1 only reduced the agglutinating power from $1: 800$ to 1 in 400 . Not the least reduction was effected by the nonabsorbing strains.

M 17 serum, titre $1: 800$, showed a trace of reduction in the highest dilutions with the negative strains and complete absorption with the positive, excepting M 43. This strain on some occasions absorbed well and on others very little.

M 15 serum had a titre of 1 in 400 and this only as the result of prolonged immunisation of the rabbit. Absorption was almost complete with all 20 strains, excepting $M 1$, with which it was slight. The nonabsorbing strains, M 16-M 46 and the inagglutinable strain of $M 6$, made not the least impression.

\section{Absorptive capacity in relation to the quantity and physical} condition of the culture used for absorption.

The question must be considered whether, since the above grouping was effected by the use of minimal quantities of absorbing culture, the differences in absorptive capacity are to any extent merely quantitative.

Further experiments have been made with the above-mentioned 22 strains upon Group I sera, to ascertain the effect of absorbing with larger amounts of culture and with unheated culture. The results are as follows, under the head of each serum:

M 1 serum. Suspensions increased to $30 \mathrm{mg}$. per c.c. and added to equal parts of $1: 25$ serum showed practically no increased absorption 
with the non-absorbing strains. Living culture added directly to the serum, the growth from a whole glucose agar tube to 1.5 c.c. of 1 in 50 dilution, gave little increase with any but M 12, which absorbed completely.

M 9 serum. The suspensions were increased to $20 \mathrm{mg}$. per c.c.; the absorption results were as before.

In an absorption experiment with M 10 serum the living growth from a whole slope (about 30-40 mg.) of each of the strains, M 14, 15, 36 , and 41 , was added to 1.5 c.c. of $1: 50$ dilution without effecting the least reduction of the agglutinin acting on $M 10$, although these strains were agglutinated to a high titre by this serum.

M 17 serum. The addition of a whole living slope culture to 1 c.c. of $1: 25$ dilution caused complete absorption in the case of M 10,12, $13,17,40$, and 43 , as before; there was very slightly increased absorption

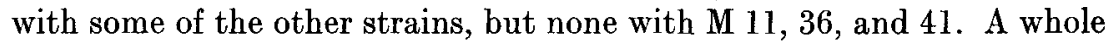
slope culture in 1 c.c. of $1: 50$ dilution gave a similar result. Still larger quantities up to two tubes per c.c. of $1: 50$ caused some reduction with M 1-9, but none with M 11,36, 41, and 46 .

The above experiments confirm the previous conclusion that the agglutinins in the various Group I sera with which the tests were made belong to three varieties with different combining qualities.

\section{Additional observations on absorptive capacities of Group I spinal strains.}

As shown in the tabular summary, p. 142 , three of the 20 strains which absorbed from one or other of the Group I sera were found to combine with all three agglutinins, designated A, B, and C. Sera were available from two of these strains, $M 10$ and $M$ 43, and it is interesting to find that at least two of the agglutinins can be demonstrated in each of the sera, i.e. there is a correspondence between absorptive and agglutinogenic capacity. Some experiments with M 10 and M 43 sera will now be described. They show incidentally that changes in the absorptive capacity of certain strains occurred during cultivation; in addition, these experiments serve to complete the classification of the remaining spinal meningococci and to define more accurately their position in the series in which Group I antigen predominates.

\section{43 serum.}

In Table VIII two separate experiments with M 43 serum are recorded. 
TABle VIII.

$M 43$ serum absorbed with 22 spinal strains. Titre of absorbed and unabsorbed serum tested on $M 43$ (different suspensions, $A$ and B).

Method. Experiment 1:2 mg. of culture (heated suspension) per c.c. of 1 in 50. Experiment 2: growth from a whole tube, 30-40 mg., added to 1.5 c.c. of 1 in 100 serum.

EXPERIMENT 1.

\begin{tabular}{|c|c|c|c|c|c|c|}
\hline \multirow{2}{*}{\multicolumn{2}{|c|}{$\begin{array}{c}\text { Absorbing } \\
\text { Strain }\end{array}$}} & & \multicolumn{2}{|c|}{ Test on M 4} & \multicolumn{2}{|c|}{ Suspension A } \\
\hline & & & 200 & 400 & 800 & 1600 \\
\hline${ }^{*} \mathrm{Nil}$ & . & . & + & + & + & + \\
\hline M I & . & . & \pm & \pm & - & - \\
\hline M 2 & . & . & + & + & tr. & - \\
\hline M 3 & . & . & + & + & + & tr. \\
\hline$M 4$ & . & . & \pm & - & - & - \\
\hline M 5 & . & . & \pm & \pm & - & - \\
\hline M 6 & . & . & + & + & + & + \\
\hline M 7 & . & . & + & \pm & tr. & - \\
\hline M 8 & . & . & \pm & \pm & - & - \\
\hline M 9 & . & . & + & \pm & \pm & - \\
\hline M 10 & . & . & + & \pm & tr. & - \\
\hline M 11 & . & - & + & + & + & \pm \\
\hline M 12 & . & . & + & + & + & + \\
\hline M 13 & . & . & + & + & + & + \\
\hline M 14 & . & . & + & + & + & + \\
\hline M 15 & . & . & + & + & + & \pm \\
\hline M I6 & . & . & + & + & + & \pm \\
\hline M 17 & . & . & + & + & + & + \\
\hline M 36 & . & . & + & + & + & \pm \\
\hline M 40 & . & . & + & + & \pm & - \\
\hline M 41 & . & . & + & + & + & + \\
\hline M 43 & . & - & + & \pm & tr. & - \\
\hline M 46 & . & . & + & + & + & + \\
\hline
\end{tabular}

EXPERIMENT 2.

$\overbrace{400}^{\text {Test on M 43. Suspension B }}$

$\begin{array}{rrrr}200 & 400 & + & \end{array}$

\pm \pm \pm tr.

$\pm \quad \pm \quad \pm$ tr.

$\pm \pm \pm \pm$

$\pm \pm \pm$

$\pm \pm \pm \quad-$

$+\quad+ \pm \pm$

\pm \pm \pm tr.

$\begin{array}{llll} \pm & \pm & \pm & \ldots\end{array}$

$\pm \quad \pm$ tr. -

$+\quad+ \pm \pm$

\pm \pm \pm tr.

- $-\quad-$

$\begin{array}{llll}- & - & -\end{array}$

$\begin{array}{llll}- & - & - & -\end{array}$

$\begin{array}{llll} \pm & \pm & \pm & \text { tr. } \\ \pm & \pm & \pm & \text { tr. }\end{array}$

$\pm \quad-\quad-$

$\pm \pm \pm \pm$

- $-\quad-$

$\pm \quad \pm \quad$ tr.

* In this and succeding tables Nil signifies that the test is upon unabsorbed serum.

The first experiment shows that the homologous agglutinin has been reduced by certain strains. A further investigation (not recorded in the table) was then made in order to render the experiment more complete, as in the case of M 10 serum (Table VII). Each heated suspension was again added to the absorbed dilutions, now $1: 50$. The test of this second absorption (not reproduced) was made on a different suspension of M 43 from the one used for the first. The result was unexpected. Instead of the agglutinating power of the serum being further reduced by those strains which absorbed after a single application of culture, it was in some cases apparently increased. On the other

$$
10-2
$$


hand, certain strains, e.g. M 12, 13, and 17, which had not at first exhibited any combining affinity for the homologous agglutinin, after the second addition absorbed the whole.

In the second experiment of Table VIII the absorption of M 43 serum was repeated with larger amounts of living culture added to the serum diluted to $1: 100$. Again the result was different from that in the first half of the table. Two strains, M 40 and M 43, which had absorbed partially at first, now absorbed the agglutinin completely; and, in addition, four strains, M 12,13,14, and 17, which had before shown no absorbing power, now effected complete absorption. The remaining strains absorbed slightly.

In seeking an explanation of these anomalous results, it was noted that the suspensions of M 43 used to test the result of absorption in the two last mentioned experiments were not the same as in the first (shown in Experiment 1 of the table), and it appeared possible that it was to this fact that the irregularity in absorption might be attributed. The exact reason of the variability did not suggest itself until it was found that later sub-cultures of M 43 differed from the earlier in absorptive capacity. This discovery at once suggested the following explanation, on the hypothesis that the antigens of M 43 had been modified during sub-culture:

(1) The original culture contained the two antigens A and B.

(2) The serum produced with this culture contained the agglutinins corresponding to both $A$ and $B$.

(3) After prolonged sub-culture changes took place in two directions, $(a)$ some strains losing the A type of antigen, and $(b)$ others losing the B type.

The evidence in support of this is:

(1) The original culture absorbed the agglutinin from an A type of serum (M 1 serum) and also from a B type of serum (M 17 serum).

(2) From M 43 serum, which agglutinated M 1 and M 17 equally, $A$ agglutinin was removed by $M 1$ whilst $B$ agglutinin was left behind, and $B$ agglutinin was removed by $M 17$, whilst $A$ agglutinin was left behind. (See p. 148.)

(3) One of the later cultures of $M 43$ absorbed the $B$ agglutinin from M 17 serum, but failed to absorb the A agglutinin from M 1 serum or from M 43 serum.

Another of the later cultures absorbed the A agglutinin from M 1 serum, but failed to absorb the B agglutinin from M 17 serum or from M 43 serum. 
In the light of this explanation the results recorded in Table VIII may be interpreted. In the first experiment the culture of M 43 used for testing the absorbed serum contained $A$ antigen alone or in predominance, and consequently registered only the absorption of agglutinin by strains possessing $A$ antigen (the strains $M 1$, etc.). In the second experiment (Table VIII) the absorbed serum was tested with a culture of $M 43$, which contained mainly $B$ antigen, and consequently registered only the absorption of agglutinin by organisms possessing B antigen (strains M 17, etc.).

Whether the two components of M 43 were present as separate individuals in the cerebro-spinal fluid of the case, or whether they are descendants from a single coccus has not been determined. There is evidence that one of the daughter strains is either still a mixture or still capable of variation, since one strain which absorbed A agglutinin but not B now absorbs B but not A. It may be assumed therefore that the differences in absorptive capacity between different sub-cultures depend upon the predominance of one or the other component.

The same explanation serves to account for another series of $a b-$ sorption tests, the results of which were at first puzzling. M 43 serum was absorbed with various strains, including M 43 , and then tested on M 7, a strain possessing A antigen. It was found that the M 43 strain failed to remove agglutinin for $M 7$. The reason, as is now evident, was that the particular strain of M 43 which was used for absorption did not contain much $\mathrm{A}$ antigen, and therefore behaved like the strains M 12, 13 and 17 (also known to possess little A antigen), and unlike M 5 (known to possess A antigen), which was found to remove the agglutinin for $M 7$.

In order to complete the classification of the remaining Group I strains the method illustrated in Table IX was used to ascertain by which of the two agglutinins (A or B) in $M 43$ serum the agglutination of a particular strain containing one of the corresponding antigens was produced. The tests with the strains M 11, 14 and 15 containing only $\mathrm{C}$ antigen are inserted as controls. Evidently M 1 contains $\mathrm{A}$ antigen and not $B$ antigen, as it removes the agglutinin for $M 8$, but not the agglutinin for M 59; for the converse reason the strains M 12, 13 and 17 contain $B$ antigen but not $A$. This method of utilising the $A$ and $B$ components of the agglutinins in M 43 serum has been applied to five other spinal strains of Group I, and has demonstrated that strains M 48, 52 and 53 contain $A$ antigen but not $B$, and that the strains $M 50$ and $M 56$ contain $B$ antigen but not $A$. 
TABLE IX.

$M 43$ serum absorbed with spinal strains representing three sub-groups of Group 1. Serum titrated before and after absorption and tested on $M 43$ (homologous), $M 8$ (combines with agglutinin $A$ ), $M 59$ (combines with agglutinin $B$ ).

Method. $5 \mathrm{mg}$. of culture (unheated suspension) per c.c. of 1 in 50 serum.

\begin{tabular}{|c|c|c|c|c|c|c|c|c|c|c|c|c|}
\hline \multirow{2}{*}{$\begin{array}{c}\text { Absorbing } \\
\text { Strain }\end{array}$} & \multicolumn{4}{|c|}{ Test on M 43} & \multicolumn{4}{|c|}{ Test on M 8} & \multicolumn{4}{|c|}{ Test on M 59} \\
\hline & 100 & 400 & 800 & 1600 & 100 & 400 & 800 & 1600 & 100 & 400 & 800 & 1600 \\
\hline Nil . & + & + & \pm & \pm & + & + & + & - & + & + & + & \pm \\
\hline M 1 & . \pm & \pm & \pm & - & - & - & - & - & + & + & + & \pm \\
\hline M 12 & . \pm & \pm & $\overline{ \pm}$ & - & + & + & + & - & - & - & - & - \\
\hline $\mathrm{B}\{\mathrm{M} 13$ & . \pm & \pm & tr. & - & + & + & \pm & - & - & - & - & - \\
\hline (M 17 & \pm & tr. & - & - & + & + & + & - & - & - & - & - \\
\hline M 11 & + & + & \pm & tr. & + & + & + & - & + & + & + & \pm \\
\hline M 14 &.+ & + & \pm & \pm & + & + & \pm & - & + & + & + & \pm \\
\hline $1 \mathrm{M} 15$ & . + & + & \pm & \pm & + & + & + & - & + & + & + & \pm \\
\hline
\end{tabular}

Certain other points of interest appear in Table IX with reference to $M 43$ serum and culture. The test suspension of $M 43$ seems to contain a proportion of $A$ antigen as well as $\mathrm{B}$, though the latter preponderates.

Although M 43 culture originally absorbed all three agglutinins, the serum produced with $\mathrm{M} 43$ does not contain much $\mathrm{C}$ agglutinin. (See Table $\mathrm{I}$ for its action upon M 11, 14 and 15.) It is possible that immunisation was not carried far enough to develop this agglutinin from the antigen shown by the original absorption test to be present.

\section{10 Serum.}

M 10 was a Group I strain with very complete antigenic properties. The evidence of this is found in the following observations, which have already been referred to; it absorbed all three agglutinins of Group I and produced a serum which agglutinated all the Group I spinal strains (see Table I). In the preceding section it has been shown that $\mathbf{M} 43$ serum contained two agglutinins, $A$ and $B$, and that the Group I strains could be divided according as they (1) picked out $\mathrm{A}$ agglutinin only; (2) B agglutinin only; or (3) failed to remove either agglutinin. Among the last-mentioned there were seven strains which possessed in addition to the above negative characteristic the capacity to absorb readily the homologous agglutinin from M 15 serum, i.e. C agglutinin.

Following the method just described in dealing with M 43 serum, it can be shown (Table $X$ ) that these seven strains, excepting $M 41$, which are not differentiated by simple agglutination tests with M 10 serum from the other two sub-groups, A and B, of Group I, fail to 


\section{F. GRIFFTth}

absorb the homologous agglutinin A from M 10 serum, but remove the agglutinin for M 14, i.e. C agglutinin.

M 41 originally gave the same reactions as the other six strains. In the experiments at this stage it had become more agglutinable, but large amounts of culture were required to remove the agglutinin for itself. When this was effected the agglutinin for other members of the sub-group $\mathrm{C}$ was also removed.

\section{TABLE X.}

$M 10$ serum absorbed with spinal strains to show the presence of two agglutinins, $A$ and $C$. Serum titrated before and after absorption and tested on $M 10$ and $M 14$.

Method. One tube of culture, $30-40 \mathrm{mg}$., added to 2.5 c.c. of 1 in 50 serum.

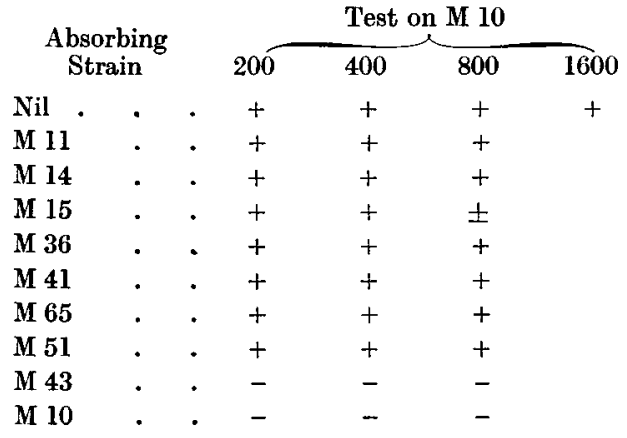

$\begin{array}{ccc}200 & 400 & 800 \\ + & + & \pm \\ - & - & - \\ - & - & - \\ - & - & - \\ - & - & - \\ + & + & \text { tr. } \\ \text { tr. } & - & - \\ - & - & - \\ - & - & - \\ - & - & -\end{array}$

\section{TABLE XI.}

$M 10$ serum absorbed with the same spinal strains as in Table IX. Serum titrated before and after absorption and tested on $M 15$ and $M 41$ (strains which combine with $C$ agglutinin).

Method. $5 \mathrm{mg}$. of culture (unheated suspension) per c.c. of 1 in 50 serum.

\begin{tabular}{|c|c|c|c|c|c|c|c|c|c|c|c|c|}
\hline \multirow{2}{*}{\multicolumn{3}{|c|}{$\begin{array}{l}\text { Absorbing } \\
\text { Strain }\end{array}$}} & \multicolumn{5}{|c|}{ Test on M 15} & \multicolumn{5}{|c|}{ Test on M 41} \\
\hline & & & 100 & 200 & 400 & 800 & 1600 & 100 & 200 & 400 & 800 & 1600 \\
\hline & Nil . & . & + & + & + & + & \pm & + & + & + & + & \pm \\
\hline d & M 1. & . & tr. & - & - & - & - & + & + & tr. & - & - \\
\hline & (M 12 & . & + & + & + & + & tr. & + & + & + & \pm & tr. \\
\hline & M 13 & . & + & + & + & + & tr. & + & + & + & \pm & \pm \\
\hline & M 17 & . & + & + & + & + & tr. & + & + & + & + & \pm \\
\hline & (M 11 & . & + & + & \pm & - & - & + & + & \pm & tr. & - \\
\hline & M 14 & . & + & + & \pm & - & - & + & + & \pm & tr. & - \\
\hline & M 15 & . & \pm & \pm & tr. & - & - & + & + & \pm & tr. & - \\
\hline
\end{tabular}


It will be seen from Table XI that while M 1 removes $\mathrm{C}$ agglutinin from M 10 serum, the three strains, $M 12,13$, and 17, fail to remove this agglutinin. But these three strains have been shown to absorb the homologous agglutinin from M 15 serum, the type serum for C agglutinin, and yet they cannot absorb from M 10 serum an agglutinin with similar combining affinities.

Assuming that in a particular strain the antigens concerned in the absorption of several agglutinins are separable substances, M 10 (combines with $\mathrm{A}$ and $\mathrm{C}$ agglutinins) and $\mathrm{M} 17$ (combines with $\mathrm{B}$ and $\mathrm{C}$ agglutinins) may be represented thus in relation to $M 15$ serum: M 10 (C antigen) absorbs M 15 agglutinin, M 17 (C antigen) absorbs M 15 agglutinin, but $M 17$ (C antigen) cannot absorb the agglutinin produced by the $C$ antigen of M 10. In explanation it may be conjectured that the antigens of $M 10$ and $M 17$, which are alike in their capacity to absorb the agglutinin from M 15 serum, possess differences in structure which are minor but sufficient to constitute a bar to the combination of the agglutinin produced by one with the antigen of the other. Similar instances of such relationship between two antigens have been found, and are reviewed in the section on variability of strains (p. 166). They serve to emphasise the need for caution in taking as a basis for division of strains into types the differences in absorptive capacities in relation to a single serum.

\section{Comparison between absorptive capacities of Group $I$ and Group II cerebro-spinal strains.}

Out of the first 46 strains of spinal meningococci, 22 , as previously stated, were selected from the results of the agglutination tests for absorption experiments with Group I sera, and all but two, M 16 and M 46, were shown to contain antigens capable of combining with the Group I agglutinins. The remaining 24, all of which were agglutinated by the Group II sera, will now be compared in respect of their capacity for absorbing agglutinin from those sera.

The method of absorption adopted in defining the agglutinins of Group I, that is, the addition of a heated suspension containing $4 \mathrm{mg}$. of culture per c.c. to an equal volume of $1: 25$ dilution of serum, was not found suited to the absorption of Group II agglutinins, since so little impression was made even with the homologous strain. It was found necessary to use larger amounts of culture. 
TABLE XII.

$M 23$ serum and $M 24$ serum (both Group II) absorbed with spinal strains of Group II. Each serum titrated and tested before and after absorption on the respective homologous strain.

Method. M 23 serum: 1.5 c.c. of 1 in 25 serum + growth from whole ascitic agar tube, approx. $30 \mathrm{mg}$. M 24 serum: $3 \mathrm{mg}$. of culture (heated suspension) per c.c. of 1 in 50 serum.

\begin{tabular}{|c|c|c|c|c|c|c|c|c|c|c|}
\hline \multirow{2}{*}{\multicolumn{3}{|c|}{$\underset{\text { Absorbing }}{\text { Strain }}$}} & \multicolumn{4}{|c|}{$\begin{array}{l}\text { M. } 23 \text { Serum } \\
\text { Test on M } 23\end{array}$} & \multicolumn{4}{|c|}{$\begin{array}{l}\text { M } 24 \text { Serum } \\
\text { Test on M } 24\end{array}$} \\
\hline & & & 100 & 200 & 400 & 800 & 100 & 200 & 400 & 800 \\
\hline Nil & . & . & + & + & + & + & + & + & + & \pm \\
\hline M 18 & . & . & \pm & \pm & \pm & tr. & \pm & \pm & tr. & - \\
\hline M 19 & . & . & \pm & \pm & \pm & tr. & + & + & \pm & $\operatorname{tr}$ \\
\hline M 20 & . & . & \pm & \pm & tr. & - & \pm & tr. & tr. & - \\
\hline M 21 & . & . & \pm & \pm & \pm & - & \pm & \pm & tr. & - \\
\hline M 22 & - & . & \pm & \pm & \pm & - & \pm & \pm & \pm & tr. \\
\hline M 23 & . & . & \pm & \pm & \pm & \pm & \pm & tr. & - & - \\
\hline M 24 & . & - & \pm & \pm & \pm & \pm & tr. & tr. & - & - \\
\hline M 25 & . & . & \pm & \pm & \pm & tr. & \pm & tr. & tr. & - \\
\hline M 26 & . & . & \pm & tr. & - & - & \pm & \pm & tr. & tr. \\
\hline M 27 & . & . & \pm & \pm & \pm & tr. & + & \pm & tr. & - \\
\hline M 28 & - & . & + & \pm & \pm & tr. & tr. & tr. & tr. & - \\
\hline M 29 & . & . & tr. & tr. & tr. & - & \pm & \pm & tr. & - \\
\hline M 30 & . & . & \pm & tr. & tr. & - & \pm & tr & tr. & - \\
\hline M 31 & . & . & + & + & + & + & + & + & + & \pm \\
\hline M 32 & · & . & + & + & + & + & + & + & + & tr. \\
\hline M 33 & . & - & + & + & + & + & + & + & + & \pm \\
\hline M 34 & - & - & + & + & \pm & tr. & + & \pm & tr. & tr. \\
\hline M 35 & . & . & + & \pm & \pm & tr. & \pm & tr. & tr. & - \\
\hline M 37 & . & . & - & - & - & - & \pm & tr. & - & - \\
\hline M 38 & - & . & tr. & - & $\rightarrow$ & - & \pm & \pm & tr. & - \\
\hline M 39 & . & - & \pm & \pm & tr. & - & \pm & \pm & tr. & tr. \\
\hline M 42 & . & . & + & + & \pm & tr. & + & \pm & \pm & tr. \\
\hline M 44 & . & . & \pm & \pm & tr. & tr. & \pm & tr. & tr. & - \\
\hline M 45 & . & . & + & \pm & tr. & tr. & \pm & \pm & tr. & tr. \\
\hline
\end{tabular}

In Table XII the results- with M 23 and M 24 sera are given. The amount of absorption from $M 23$ serum ranges from slight diminution of agglutination in the highest dilutions in the case of M 35 to complete absorption with M 37. After absorption with certain strains including the homologous, the test suspension was still agglutinated to the same height as before absorption, but agglutination was incomplete in every dilution. Three strains only, M 31,32, and 33, failed to absorb any of the agglutinin for M 23 . A similar result was obtained with M 24 
serum, the same three strains again failing to absorb appreciably. Thus 21 out of the 24 strains showed similar but not identical absorbing capacities in relation to the two Group II sera.

Comparing the absorption experiments with Group I sera, it was found that one serum, M 15, was absorbed by all except two of the 22 strains in Group I. But absorption experiments upon sera prepared with other individuals of the 20 strains showed that these could be divided into three sub-groups. Similarly, the Group II strains may be subdivided according to their absorptive capacities for the various Group II sera. M 18, for example, produced a serum from which only a minority of the above strains extracted an appreciable amount of homologous agglutinin.

\section{TABLE XIII.}

Four Group II sera absorbed with the same suspensions of nine spinal strains. Each serum titrated before and after absorption and tested on the respective homologous strain.

Method. M 32 serum: $10 \mathrm{mg}$. of culture per c.c. of 1 in 100 . M 18 serum: $10 \mathrm{mg}$. of culture per c.c. of 1 in 100 . M 33 serum: $10 \mathrm{mg}$. of culture per c.c. of 1 in 100. M 24 serum: 5 mg. of culture per c.c. of 1 in 50.

\begin{tabular}{|c|c|c|c|c|c|c|c|c|c|c|c|c|c|c|c|}
\hline \multirow{2}{*}{$\begin{array}{l}\text { Absorbing } \\
\text { Strain }\end{array}$} & \multirow{2}{*}{\multicolumn{3}{|c|}{$\overbrace{200400800}^{\begin{array}{c}\text { M } 32 \text { Serum } \\
\text { Test on M } 32\end{array}}$}} & \multicolumn{4}{|c|}{$\begin{array}{l}\text { M } 18 \text { Serum } \\
\text { Test on M } 18\end{array}$} & \multicolumn{4}{|c|}{$\begin{array}{l}\text { M } 24 \text { Serum } \\
\text { Test on M } 24\end{array}$} & \multicolumn{4}{|c|}{$\begin{array}{c}\text { M } 33 \text { Serum } \\
\text { Test on M } 33\end{array}$} \\
\hline & & & & 200 & 400 & 800 & 1600 & 100 & 200 & 400 & 800 & 200 & 400 & 800 & 1600 \\
\hline Nil & + & + & + & + & + & + & + & + & + & + & + & + & + & + & \pm \\
\hline M 9 & + & + & \pm & + & + & + & + & + & + & + & tr. & + & + & tr. & - \\
\hline M 18 & + & + & \pm & - & - & - & - & \pm & \pm & tr. & - & \pm & \pm & tr. & - \\
\hline ห 20 & + & + & \pm & + & + & + & \pm & + & + & \pm & - & + & + & \pm & tr. \\
\hline M 21 & + & + & \pm & + & + & + & \pm & + & \pm & tr. & - & + & + & \pm & tr. \\
\hline II 24 & + & + & \pm & + & + & + & \pm & tr. & - & - & - & \pm & tr. & tr. & - \\
\hline M 31 & . + & + & \pm & + & + & + & + & $t$ & \pm & tr. & - & \pm & \pm & tr. & tr. \\
\hline M 32 & . - & - & - & + & + & + & \pm & + & \pm & tr. & - & + & \pm & \pm & tr. \\
\hline M 33 & + & + & \pm & + & + & \pm & - & + & + & tr. & - & \pm & tr. & - & - \\
\hline 142 & + & + & tr. & + & + & + & \pm & tr. & - & - & - & + & + & \pm & tr. \\
\hline
\end{tabular}

Table XIII shows that there are at least four different Group II agglutinins. Four sera were absorbed, each with the same suspensions of the same strains; the amount of culture used was sufficient or almost sufficient to exhaust the sera in the case of the respective homologous strains. Among those strains not absorbing the homologous agglutinin of M 18 serum is M 24, although M 18 was found to absorb the agglutinin from M 24 serum; this relationship between two strains and their 
respective sera has been repeatedly observed. M 31, 32, and 33 are seen to be capable of partially absorbing M 24 serum when added in larger amounts than were used previously (Table XII). Complete absorption of M 18 and M 32 sera was effected only by the homologous strains. M 33 agglutinin was absorbed to some extent by all the strains, including M 9 (Group I), thus connecting the two groups.

\section{TABLE XIV.}

M 24 serum (Group II) absorbed with seven spinal strains representing three sub-groups of Group I. Serum titrated before and after absorption and tested on $M$ 18, M 61, and the homologous strain (all Group II).

Method. $10 \mathrm{mg}$. of culture (unheated suspension) per c.c. of 1 in 50 serum.

\begin{tabular}{|c|c|c|c|c|c|c|c|c|c|c|c|c|c|}
\hline \multirow{2}{*}{\multicolumn{2}{|c|}{$\begin{array}{c}\text { Absorbing } \\
\text { Strain }\end{array}$}} & \multicolumn{4}{|c|}{ Test on M 24} & \multicolumn{4}{|c|}{ Test on M 18} & \multicolumn{4}{|c|}{ Test on M 61} \\
\hline & & 100 & 200 & 400 & 800 & 100 & 200 & 400 & 800 & 100 & 200 & 400 . & 800 \\
\hline Nil & . . & + & + & + & \pm & + & + & + & \pm & + & + & + & + \\
\hline 11 & . & + & + & \pm & \pm & + & + & + & \pm & + & + & + & \pm \\
\hline 112 & . & + & + & \pm & \pm & + & + & + & \pm & + & + & + & \pm \\
\hline M 13 & . & + & + & + & \pm & + & + & \pm & \pm & + & + & + & \pm \\
\hline 17 & & + & + & \pm & \pm & + & + & + & \pm & + & + & + & \pm \\
\hline 11 & - & + & + & \pm & - & + & + & \pm & tr. & + & + & + & \pm \\
\hline 14 & . & + & \pm & \pm & - & + & + & \pm & tr. & + & + & + & \pm \\
\hline M 15 & . & . + & \pm & \pm & - & + & + & \pm & tr. & + & + & + & tr. \\
\hline
\end{tabular}

A further link between the two groups is shown in Table XIV. M 24 serum was absorbed, titrated, and tested on three strains of Group II, the dilutions being identical in each case. It is seen that the Group I strains, M 11, 14, and 15 removed from the serum a little of the agglutinin for M 24 and a trace for M 18. With larger amounts of culture the absorption of M 24 agglutinin was increased (Table XV).

\section{Table XV.}

$M 24$ serum absorbed with increased quantilies of three spinal strains (see Table XIV). Titre of serum before and after absorption for the homologous strain.

Method. Growth from one tube to 2 c.c. of 1 in 50 .

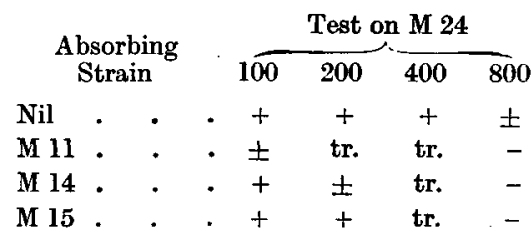




\section{Agglutinin absorption with naso-pharyngeal strains.}

The preceding experiments on absorption with spinal meningococci have shown that many differences exist between the absorptive capacities of different strains and that for the accurate definition of these a large number of sera is required. This fact, on the one hand, indicates that the difficulty will necessarily be as great, and is likely to be greater, in applying the same methods to the identification of many of the nasopharyngeal strains with meningococci from the cerebro-spinal fluid of cases of meningitis; and, on the other hand, it emphasises the danger of error in excluding the former from the meningococcus species on the grounds of their failure to absorb agglutinin from a few standard sera. In the light of the data ascertained as to the combining affinities of the agglutinin in a number of spinal meningococcus sera, the present task is to compare the combining capacities of the pharyngeal strains for those agglutinins, or, alternatively, to test the absorbing power of spinal strains upon sera prepared with pharyngeal strains. The spinal Group II agglutinating sera, with which a large number of pharyngeal strains have been shown to react (Table II), will be dealt with in the first place.

\section{Relationship of the naso-pharyngeal strains to the agglutinins of Group II.}

\section{(1) Tests with $M 24$ serum.}

The majority of the pharyngeal strains which were agglutinated by M 24 serum were tested as to their absorptive capacity for the homologous agglutinin. It was found that M 24 itself reduced the agglutinating titre of the serum below 1-100, when added in the proportion of $5 \mathrm{mg}$. of culture to each c.c. of 1-50 dilution of serum; and this method was adopted in the case of the pharyngeal strains. For the sake of condensation only a few of the results are given in tabular form. These are representative of the whole series and are shown in Table XVI, from which it will be seen that some strains caused complete absorption, some partial, and others were negative. The absorbed dilutions were titrated in duplicate and were tested on M 23 as well as on the homologous strain; the results as a rule agreed. 


\section{Table XVI.}

$M 24$ serum absorbed with 13 naso-pharyngeal strains. Serum titrated before and after absorption and tested on $M 24$ and $M 23$.

Method. $5 \mathrm{mg}$. of culture (unheated suspension) per c.c. of 1 in 50 serum.

\begin{tabular}{|c|c|c|c|c|c|c|c|c|}
\hline \multirow{2}{*}{\multicolumn{2}{|c|}{$\begin{array}{c}\text { Absorbing } \\
\text { Strain }\end{array}$}} & \multicolumn{3}{|c|}{ Test on M 24} & \multicolumn{4}{|c|}{ Test on M 23} \\
\hline & & 100 & 200 & 400 & 100 & 200 & 400 & 800 \\
\hline Nil. & . & + & + & + & + & + & + & + \\
\hline NP 1 & . & + & + & + & + & + & + & + \\
\hline NP 3 & . & + & + & + & + & + & + & + \\
\hline NP 8 & . & \pm & tr. & - & + & + & \pm & tr. \\
\hline NP 10 & . & . tr. & - & - & + & + & \pm & - \\
\hline NP 47 & . & - \pm & tr. & tr. & + & \pm & tr. & - \\
\hline NP 58 & . & + & + & + & + & + & + & \pm \\
\hline NP 60 & . & + & + & \pm & + & + & + & tr. \\
\hline NP 72 & . & - & - & - & - & - & - & - \\
\hline NP 73 & . & tr. & tr. & - & + & + & \pm & - \\
\hline NP 78 & . & - & - & - & + & + & tr. & - \\
\hline NP 80 & . & \pm & tr. & - & tr. & - & - & - \\
\hline NP 87 & - & tr. & tr. & - & - & - & - & $\cdots$ \\
\hline NP 85 & . & . \pm & tr. & - & + & + & $t$ & $\ldots$ \\
\hline
\end{tabular}

The following is a summary of the complete results by this method of absorption:

Total strains tested, 58 .

Negative: 10 strains (NP 1, 3, 15, 19, 21, 33, 46, 58, 71 and 86).

Definitely positive, i.e. reduction in titre to incomplete at 1:100: 23 strains (NP 7, 8, 9, 10, 28, 34, 35, 37, 38, 45, 47, 50, 62, 72, 73, 74, $78,80,83,85,87$ and 89$)$.

Slight absorption: 25 strains. The absorption with these was generally increased with larger quantities of culture; for example, the whole growth from a glucose ascitic slope added to 1 c.c. of 1-50 completely exhausted the serum in the case of NP 2, 20,23, 25, 26 and 27. If spinal and pharyngeal strains agglutinated by Group II sera are compared as a whole, there will be found close agreement in respect of their absorbing capacities for the homologous agglutinin of $M 24$ serum. It was shown. that 21 out of 24 agglutinating spinal strains definitely absorbed the agglutinin from this serum, and the remaining three also absorbed when the amount of culture was increased.

(2) Tests with $M 18$ serum.

This serum agglutinated 32 out of the 86 pharyngeal strains to $1-400$ or over. The absorptive capacities of 15 were tested in relation 
to this serum. Seven of these, NP $46,58,64,72,78,85$ and 87 , failed to absorb the homologous agglutinin. The results with the eight other strains are shown in Table XVII, in which are included for comparison nine spinal strains of Group II. The table is arranged in a different manner from any of the others. The first column enumerates the pharyngeal and spinal strains agglutinated by the serum, before absorption, up to 1-800 at least, each suspension being the same throughout the experiment. The rest of the table shows that certain of these strains agglutinated $(+)$ and others failed to agglutinate $(-)$ in a dilution of 1-200 after absorption with the strain at the head of each column. Thus in the second column, showing the results of absorption with NP 10, all except NP 40 failed to agglutinate in 1-200. The amount of culture used for absorbing extracted completely (i.e. in the highest concentration of serum tested) the agglutinin for the absorbing strain in every instance excepting NP 35; in a few cases where the results were not quite sharp, a trace of agglutination was taken as negative and a marked though incomplete reaction as positive.

\section{TABLe XVII.}

$M 18$ serum absorbed with spinal and pharyngeal strains.

Method. $10 \mathrm{mg}$. of culture (unheated suspension) per c.c. of 1 in 100 serum. All the strains in the first column were agglutinated to 1 in 800 at least before absorption. Table shows the agglutination $(+$ or - ) in 1 in 200 dilution after absorption with the strains at the head of each succeeding column after the first.

$\begin{array}{lcccccccccccc} & \text { NP } & \text { NP } & \text { NP } & \text { NP } & \text { NP } & \text { NP } & \text { NP } & \text { NP } & \text { M } & \text { M } & \text { M } & \text { M } \\ & 10 & 28 & 35 & 54 & 80 & 48 & 73 & 40 & 64 & 66 & \mathbf{2 2} & 33 \\ \text { NP 10 } & - & + & + & + & - & - & + & + & + & - & - & + \\ \text { NP 28 } & - & - & + & - & - & - & + & + & - & + & - & - \\ \text { NP 35 } & - & + & + & - & - & - & - & + & + & - & - & + \\ \text { NP 54 } & - & - & + & - & + & - & + & + & - & + & - & - \\ \text { NP 80 } & - & + & + & - & - & - & - & + & + & - & - & + \\ \text { NP 48 } & - & + & + & + & - & - & + & + & + & + & - & + \\ \text { NP 73 } & - & - & + & - & - & - & - & + & + & - & - & + \\ \text { NP 40 } & + & + & + & - & + & - & + & - & - & - & + & - \\ \text { M 18 } & - & + & + & - & - & - & - & + & + & + & - & + \\ \text { M 27 } & - & + & + & - & - & - & + & + & + & + & - & + \\ \text { M 61 } & - & + & + & - & - & - & + & + & - & + & - & + \\ \text { M 33 } & - & - & + & - & - & - & + & + & - & + & - & - \\ \text { M 26 } & - & + & + & + & + & - & + & + & + & + & - & + \\ \text { M 28 } & - & + & + & + & - & - & - & + & + & - & - & + \\ \text { M 29 } & - & + & + & + & - & - & + & + & + & - & - & + \\ \text { M 37 } & - & + & + & - & - & - & & + & + & - & - & + \\ \text { M 44 } & - & + & - & - & - & - & - & + & + & - & - & +\end{array}$


The results show that five pharyngeal strains, NP 10, 54, 80, 48 and 73 , and one spinal strain, M 22, have removed the agglutinin for themselves and at the same time the homologous agglutinin. They differ in capacity for absorbing agglutinins which act upon strains other than the homologous. This somewhat anomalous result may be due to incomplete exhaustion of the serum and the presence of small quantities of agglutinin still remaining, which influences some strains more strongly than others. The strains can be arranged in a series with diminishing capacity for absorption; NP 48 absorbs the agglutinin for all the strains in the left-hand column, and is followed closely by NP 10 and M 22, while NP 40 removes only the agglutinin for itself.

Certain conclusions are to be drawn from these results. (1) No distinction can be made between the spinal and pharyngeal strains; (2) grouping by this method of absorption is indistinct; and (3) differences in absorptive capacity are revealed.

\section{(3) $M 32$ serum and $M 33$ serum.}

Certain pharyngeal strains agglutinated by the above two sera were identified by absorption tests with the spinal strains which produced these sera.

M 32 serum was absorbed with that amount of culture which sufficed in the case of the homologous strain to remove the agglutinin for itself. With this quantity three spinal strains, M 23,38 and 66, and three pharyngeal strains, NP 5, 12 and 81 removed completely the homologous agglutinin.

The agglutinin from M 33 serum was completely removed by M 24, NP 62 and NP 39. Under the same conditions certain other spinal and pharyngeal strains reduced the homologous agglutinin from 1-1600 to $1-800$ and $1-400$.

\section{Summary.}

$A$ general survey of these results shows that 33 of the 86 pharyngeal strains have exhausted the homologous agglutinin of one or more of the four Group II spinal sera. No less than 29 other pharyngeal strains, not included in the above 33, were agglutinated up to $1: 400$, or in even higher dilutions. It has not seemed to me a profitable task, considering the range of variation in absorptive capacity of the spinal strains themselves, to attempt to "place" all these strains. I am of the opinion that the results obtained are sufficient to justify the conclusion that a strain which agglutinates to $1: 400$ with one or more sera of Group II will be found to absorb agglutinin from some one or other Group II serum. 


\section{Relationship of pharyngeal strains to the agglutinins of Group $I$.}

The simple agglutination tests summarised in Tables I and II have shown that the proportion of strains in the pharyngeal series which are agglutinated completely to 1-400 and over by Group I sera is much lower than that in the spinal series, comprising in the latter 27 out of 66 strains, and in the former 8 out of 86 . Evidence of affinities in the pharyngeal strains with the spinal antigen of Group I, though not revealed by simple agglutination, has been indicated by the agglutinogenic tests, and confirmation is furnished by the experiments on agglutinin absorption. The results with a number of pharyngeal strains, in which such evidence has. been sought, are summarised in Table XVIII. The agglutination reactions of the above strains to the two group sera are contrasted with their capacities to absorb agglutinin from these sera and to produce agglutinin for spinal strains of Group I. For convenience, the associated affinity, when demonstrated, with spinal sera of Group II is included in the table and will be discussed later.

It will be seen from this table that the three pharyngeal strains, NP 1, 53, and 40, were capable of binding one or more of the Group I agglutinins, A, B and C. NP 1 and 53 removed the agglutinins for M 1 and $M 15$ (i.e. $\mathrm{A}$ and $\mathrm{C}$ agglutinins), and NP 40 removed the agglutinin for $\mathrm{M} 15$ (i.e. $\mathrm{C}$ agglutinin only). As regards $\mathrm{B}$ agglutinin (corresponding to $M 17$ antigen), no pharyngeal strain is quite equal to $M 17$ in capacity for absorbing B agglutinin from M 17 serum, but partial though distinct absorption was produced by several strains. The results are given later in detail.

A few pharyngeal strains therefore possess, like all but two of the spinal Group I strains, capacity to absorb one or more of the three Group I agglutinins. The two exceptional spinal strains which failed in this capacity are $M 16$ and $M 46$. The question now arises whether there are in the naso-pharyngeal series strains which stand in the same relation as M 16 and M 46 to the majority of the spinal Group I strains, i.e. possess antigens related to but not identical with those producing the three agglutinins of Group I. It has been found, as indicated in the table, that these specialised antigens of M.16 and M 46 are represented respectively in two pharyngeal strains, NP 2 and NP 43. The method of identification is described in the following experiments in which each strain is dealt with separately: 
TABLE XVIII.

Table showing evidence of serological relationship of naso-pharyngeal strains to spinal strains of Group I, and associated affinity with Group II strains.

\begin{tabular}{|c|c|c|c|c|}
\hline \multirow[b]{2}{*}{ Strains } & \multicolumn{2}{|c|}{$\begin{array}{l}\text { Highest agglutination } \\
\text { with sera of }\end{array}$} & \multirow[b]{2}{*}{$\begin{array}{l}\text { Absorptive and agglutinogenic } \\
\text { relationship to Group I }\end{array}$} & \multirow[b]{2}{*}{ Affinity with Group II } \\
\hline & Group I & $\overline{\text { Group II }}$ & & \\
\hline NP 1 & $1: 800$ & 一 & $\begin{array}{l}\text { M } 1 \text { and M } 15 \text { sera completely } \\
\text { absorbed }\end{array}$ & \\
\hline NP 53 & $1: 1000$ & $1: 200$ & $\begin{array}{l}\text { M } 1 \text { and M } 15 \text { sera completely } \\
\text { absorbed }\end{array}$ & \\
\hline NP 67 & 一 & $1: 200$ & $\begin{array}{l}\text { M } 17 \text { and M } 43 \text { sera partially } \\
\text { absorbed }\end{array}$ & \\
\hline NP 2 & $1: 400$ & $1: 400$ & $\begin{array}{l}\text { M } 16 \text { serum completely ab- } \\
\text { sorbed }\end{array}$ & $\begin{array}{l}\text { M } 24 \text { serum partially } \\
\text { absorbed }\end{array}$ \\
\hline NP 3 & $I: 400$ & $I: 400$ & M 17 and $M 43$ sera partially & M 33 serum absorbed \\
\hline $\begin{array}{l}\text { NP } 4 \\
\text { NP } 65\end{array}$ & $\begin{array}{l}1: 400 \\
1: 1000\end{array}$ & $\begin{array}{l}1: 800 \\
1: 800\end{array}$ & absorbed & by NP 4 \\
\hline NP 41 & $1: 400$ & $1: 400$ & $\begin{array}{l}\text { Produces agglutinin for Group } \\
\text { I. NP } 41 \text { serum completely } \\
\text { absorbed by M } 15\end{array}$ & $\begin{array}{l}\text { Produces agglutinin for } \\
\text { Group II }\end{array}$ \\
\hline NP 5 & $1: 200$ & $1: \mathbf{4 0 0}$ & $\begin{array}{l}\text { M } 17 \text { and M } 43 \text { sera partially } \\
\text { absorbed }\end{array}$ & $\begin{array}{l}\text { M } 32 \text { serum completely } \\
\text { absorbed: M } 24 \text { and } \\
33 \text { sera partially ab- } \\
\text { sorbed }\end{array}$ \\
\hline NP 40 & $1: 100$ & $1: 1000$ & $\begin{array}{l}\text { Produces agglutinins for } \\
\text { Group I. M } 15 \text { serum com. } \\
\text { pletely absorbed }\end{array}$ & $\begin{array}{l}\text { Produces agglutinins } \\
\text { for Group II. M } 24 \\
\text { and } 33 \text { sera partially } \\
\text { absorbed }\end{array}$ \\
\hline NP 71 & $1: 200$ & $1: 100$ & $\begin{array}{l}\text { M } 17 \text { and M } 43 \text { sera partially } \\
\text { absorbed }\end{array}$ & \\
\hline NP 11 & - & $1: 200$ & $\begin{array}{l}\text { Produces .agglutinins for } \\
\text { Group I. M } 17 \text { serum par- } \\
\text { tially absorbed. NP } 11 \\
\text { serum completely absorbed } \\
\text { by } M 17 \text { and M } 46\end{array}$ & $\begin{array}{l}\text { Produces agglutinins } \\
\quad \text { for Group II }\end{array}$ \\
\hline NP 36 & 一 & $1: 400$ & 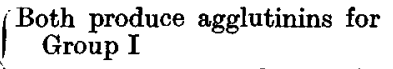 & $\begin{array}{l}\text { Produce agglutinins for } \\
\text { Group II }\end{array}$ \\
\hline NP 43 & 一 & $1: 400$ & $\begin{array}{l}\text { NP } 43 \text { serum completely ab- } \\
\text { sorbed by M } 46\end{array}$ & \\
\hline NP 82 & 一 & - & $\begin{array}{l}\text { M } 43 \text { and M } 10 \text { sera partially } \\
\text { absorbed }\end{array}$ & \\
\hline NP 86 & - & - & M 43 serum partially absorbed & \\
\hline NP 44 & - & $1: 100$ & $\begin{array}{l}\text { Produces agglutinins for } \\
\text { Group I. NP 44 serum ab- } \\
\text { sorbed by M 48, Group I }\end{array}$ & $\begin{array}{l}\text { Produces agglutinins } \\
\text { for Group II. M 33 } \\
\text { serum partially ab. } \\
\text { sorbed }\end{array}$ \\
\hline
\end{tabular}

\section{NP 2.}

NP 2, which was agglutinated by Group I and Group II sera, absorbed partially the homologous agglutinin both from M 24 and M 33 serum (Group II), but did not remove any of the three agglutinins

Journ. of Hyg. xviI 
of Group I. M 16 serum (titre $1: 1600$ ), agglutinated NP 2 to $1: 800$. From this serum NP 2 absorbed the homologous agglutinin almost as well as M 16 itself. The only spinal strains which absorbed M 16 agglutinin were M 15 and M 36, and they only reduced the titre from $1: 1600$ to $1: 400$ by a single application of culture.

NP 43.

In Table XIX M 46 is shown to be almost identical with NP 43 in its capacity for absorbing the homologous agglutinin from NP 43 serum. No other single spinal strain tested was found to remove completely the homologous agglutinin, even when added in large amounts and on successive occasions.

\section{TABLE XIX.}

NP 43 serum absorbed with twelve spinal strains. Titre of serum before absorption (1 in 1600) and after absorption when tested on the homologous strain.

Method. $10-20 \mathrm{mg}$. of living culture per c.c. of 1 in 50 serum.

\begin{tabular}{|c|c|c|c|c|c|c|}
\hline \multirow{2}{*}{\multicolumn{3}{|c|}{ Absorbing Strain }} & & \multicolumn{3}{|c|}{ Test on NP 43} \\
\hline & & & & 100 & 400 & 800 \\
\hline Nil & . & . & . & + & + & + \\
\hline M 9 & . & . & . & + & + & + \\
\hline M 12 & . & . & . & + & + & + \\
\hline M 15 & . & . & . & + & + & + \\
\hline M 16 & . & . & . & + & + & + \\
\hline M 17 & . & . & . & + & + & + \\
\hline M 18 & . & . & . & + & + & \pm \\
\hline M 24 & . & . & . & + & + & \pm \\
\hline M 32 & . & . & . & + & + & + \\
\hline M 33 & . & . & . & + & + & + \\
\hline M 38 & . & . & . & + & + & + \\
\hline M 46 & . & . & • & \pm & tr. & - \\
\hline M 64 & . & & & + & + & + \\
\hline NP 43 & . & . & . & tr. & tr. & - \\
\hline
\end{tabular}

Relationship of other pharyngeal strains to spinal strains.

NP 11.

NP 11 was nearly two years in culture, during which it underwent some modification. Originally it was agglutinated by Group II sera and not by Group I. A serum prepared with it agglutinated more strongly the spinal strains of Group I than those of Group II. After 
a time NP 11 lost its agglutinability to its own serum and a second serum was prepared from it. The second serum was much more quickly produced than the first, and attained a titre of 1-2000. This serum, five times the titre of the first, only agglutinated up to 1-100 those spinal strains of Group I which were agglutinated to the full titre of the first serum. In Table $\mathrm{XX}$ is given an absorption experiment with the first serum, the absorbed dilutions being tested on M 10 and M 56 (Group I) in addition to the homologous strain, which at that time was unfortunately only slightly agglutinable. M 46, which was agglutinated completely to 1-400, absorbed the agglutinin as well as NP 11. It is shown also that M 17 absorbed the agglutinin equally well, although NP 11 can only partially absorb M 17 serum; M 46 was unable to effect any absorption from $\mathrm{M} 17$ serum.

\section{TABLE XX.}

NP 11 serum absorbed with five spinal strains. Serum titrated beforc and after absorption and tested on $M 10, M 56$ and $N P 11$.

Method. $20 \mathrm{mg}$. of living culture per c.c. of 1 in 50 serum.

\begin{tabular}{|c|c|c|c|c|c|c|c|c|c|c|}
\hline \multirow{2}{*}{\multicolumn{2}{|c|}{ Absorbing Strain }} & \multicolumn{3}{|c|}{ Test on M 10} & \multicolumn{4}{|c|}{ Test on M 56} & \multicolumn{2}{|c|}{ Test on NP 11} \\
\hline & & 100 & 200 & 400 & 100 & 200 & 400 & 800 & 100 & 200 \\
\hline $\mathrm{Nil}$ & . . & + & + & + & + & + & + & \pm & + & \pm \\
\hline NP 11 & . & - & - & - & \pm & - & - & - & - & $=$ \\
\hline M 17 & . & - & - & - & tr. & - & - & - & tr. & - \\
\hline M 46 & . & - & - & - & - & - & - & - & - & - \\
\hline M 9 & . & + & \pm & tr. & + & \pm & - & - & \pm & \pm \\
\hline M 14 & . & + & + & tr. & + & + & + & - & \pm & \pm \\
\hline M 15 & . & + & + & tr. & + & \pm & tr. & - & \pm & \pm \\
\hline
\end{tabular}

NP 5.

NP 5, which absorbs readily the homologous agglutinin of M 32 (Group II), removes partially M 17 agglutinin (agglutinin B of Group I). Complete absorption of the serum was obtained when the dose of culture was increased beyond that required to exhaust M 17 serum with M 17 itself.

NP 41.

NP 41, which was agglutinated to $1-400$ by M 10 serum, did not remove from that serum either the agglutinin for $M 10$ or that for $M 15$; it failed also to remove the homologous agglutinin from M 15 serum. A serum prepared with NP 41 agglutinated M 15 and NP 41 equally well, the reaction being complete in 1-400, well marked in 1-800. It 
was found that M $1 \tilde{5}$ was identical with NP 41 in removing the homologous agglutinin from that serum. A second interesting anomaly was observed in that the six strains, M 1-M 6, could not remove from NP 41 serum the agglutinin for $M 15$, although they removed from $M 15$ serum the agglutinin for M 15 (see p. 142).

NP 40.

NP 40 readily removed the homologous agglutinin from M 15 serum, but the spinal strain could not remove the homologous agglutinin from the pharyngeal serum. This relationship is similar to that between NP 41 and M 15, but in the reverse direction.

NP 44.

NP 44 was scarcely agglutinated by any of the spinal sera, but produced a serum which agglutinated to a high titre spinal strains in both groups. The homologous agglutinin of NP 44 serum was absorbed with difficulty, many strains of Group I producing no result. The whole of a plate culture of $M 11$ added to 2 c.c. of 1 in 50 dilution only reduced the homologous agglutinin from 1-800 to 1-400. Three strains of Group I gave the following result (absorption with $10 \mathrm{mg}$. of culture per c.c. of 1-100 dilution): M 48 absorbed completely, M 9 was less effective, and M 41 reduced the titre for the homologous strain from $1-800$ to $1-400$. These strains varied at different times in their capacity for absorbing the serum. The homologous strain itself required to be added in considerable amounts to the serum to produce marked absorption; for example, after absorption with $20 \mathrm{mg}$. of culture per c.c. of 1-50 dilution, the homologous strain was still agglutinated to the full titre but incompletely in each dilution.

\section{Pharyngeal strains related to $M 17$ and $M 43$.}

It has been mentioned earlier that a number of pharyngeal strains had a certain combining affinity for agglutinin B in M 17 and M 43 sera. The method of absorption adopted to show the presence of two agglutinins in M 43 serum was followed in the case of certain pharyngeal strains. As shown in Table XXI, M 43 serum was absorbed by five pharyngeal strains and in addition by a number of spinal strains which served as controls. The absorbed serum dilutions were titrated in duplicate and tested on M 43 and M 12. It is shown that M 65, 51, and 64 caused no significant diminution in the agglutinating power of the serum either for M 43 or M 12. M 48 and M 43 absorbed the agglutinin 
for M 43 (A agglutinin), and left that for M 12 intact, while M 17 absorbed only M 12 agglutinin (B agglutinin). (The suspension of M 43 used contained the component corresponding to $\mathrm{M} 1$, and therefore registered only the absorption of A agglutinin.) Of the pharyngeal strains, NP 65, 67 , and 71 reduced by half $\mathrm{B}$ agglutinin, i.e. the agglutinin for $\mathrm{M} \mathrm{12}$; the other two pharyngeal strains had practically no effect.

\section{TABLE XXI.}

Absorption of M 43 serum with spinal and pharyngeal strains, showing the presence of the two agglutinins $A$ and $B$. Serum titrated before and after absorption and tested on $M 43$ and $M 12$.

Method. $5 \mathrm{mg}$. of culture (unheated suspension) per c.c. of 1 in 50 serum.

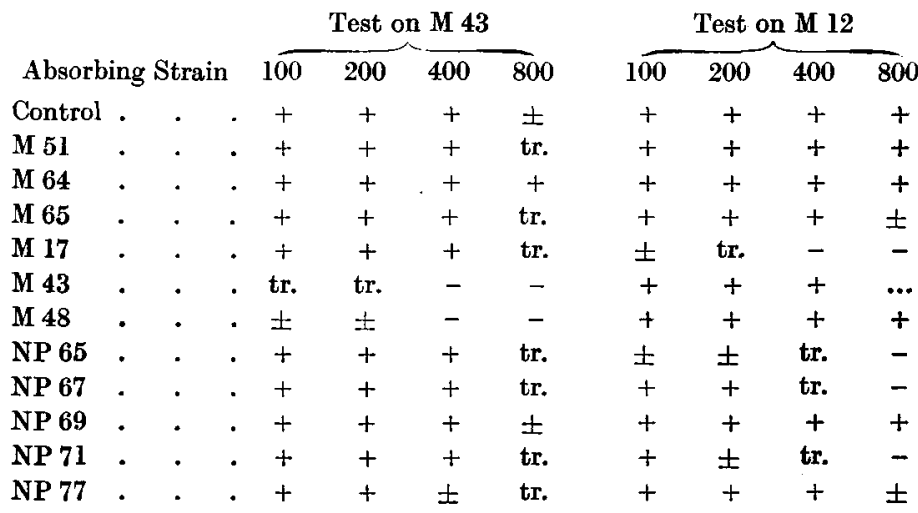

In addition to the above, other strains which partially removed from M 43 serum the agglutinin for M 17 were NP 5, 52, 82, and 86 .

A second experiment with M 43 serum is shown in Table XXIA. In this example the absorbed dilutions were tested on M 50, a culture which was shown to exhaust M 17 serum. There was distinct absorption with NP 11 and NP 14 (the latter strain was agglutinated to 1-400 by M 43 serum).

The next step was to absorb M 17 serum with the pharyngeal strains which had been shown as above to be related to M 17 through their absorptive capacity for the agglutinin in M 43 serum, which acts upon M 17. It was found that these pharyngeal strains reduced to a varying extent the homologous agglutinin of M 17 serum, but failed to exhaust it completely. Several, however, extracted completely from M 17 serum the agglutinin for M 12 (identical in absorptive capacity with M 17), 
Table XXIa.

M 43 serum absorbed with five naso-pharyngeal strains. Serum titrated before and after absorption and tested on $M 50$ (M 50 absorbed $M 17$ agglutinin).

Method. $2 \mathrm{mg}$. of culture (heated suspension) per c.c. of 1 in 100 serum.

\begin{tabular}{|c|c|c|c|c|c|}
\hline \multirow{2}{*}{\multicolumn{2}{|c|}{ Absorbing Strain }} & \multicolumn{4}{|c|}{ Test on M 50} \\
\hline & & 200 & 400 & 800 & 1600 \\
\hline Nil . &.$\quad$. & + & + & + & \pm \\
\hline NP 2 & . & + & + & \pm & - \\
\hline NP 4. & . & + & + & + & + \\
\hline NP 11. & . & + & \pm & - & - \\
\hline NP 14. & . & + & \pm & - & - \\
\hline NP 19. & . & + & + & + & \pm \\
\hline M 43 . & . & tr. & - & - & - \\
\hline
\end{tabular}

and other strains reduced the agglutinin for $\mathrm{M} 50$, a strain similar to M 12.

Briefly stated, the results of experiments of this nature showed that the agglutinins in M 17 serum which acted upon spinal strains related to $\mathrm{M} 17$ in absorptive capacity cannot be a single entity, but must comprise a group of agglutinins differing slightly from each other in combining qualities. The related pharyngeal strains have apparently greater affinity for certain of these agglutinins than for others. This question will be reverted to in the section on variability of serological characteristics.

\section{Evidence of association of Group I and Group II antigens in a single strain.}

The agglutination and agglutinogenic tests have shown that both group antigens may be present in a single meningococcus strain, the evidence being most marked in the case of certain less typical spinal strains and in a considerable proportion of the naso-pharyngeal strains. The predominance of one antigen over the other in the typical spinal strains has been generally so definite that cross-absorption tests with their sera have given negative results. The spinal strains of Group I which absorb $\mathrm{C}$ but not $\mathrm{A}$ or $\mathrm{B}$ agglutinin form an exception, since they can remove the agglutinin from M 24 serum (Group II) (see Table XV).

Special attention has been directed to those pharyngeal strains which produce agglutinins for spinal strains of both groups and are sometimes 
agglutinated by both group sera. Reference has already been made to certain of these in Table XVIII, and some details of interest will now be considered.

NP 44 serum agglutinated M 18 (Group II) up to $1: 800$. M 24 and $M 23$ readily removed this agglutinin, and $M 9$ (Group I) reduced it by half. NP 41 agglutinated M 21 (Group II) and M 15 (Group I) removed this agglutinin as well as that for the homologous strain. NP 43 agglutinated a Group II spinal strain, M 61, to $1: 800$. Two other Group II spinal strains readily absorbed from NP 43 serum the agglutinin for M 61 while only reducing the homologous agglutinin from $1: 1600$ to $1: 800$. M 9 (Group I), on the other hand, absorbed the agglutinin for itself, but did not affect either the agglutinin for M 61 or NP 43.

A further observation of interest in this connection is that a mixture of Group I and Group II strains was often more effective in reducing the homologous agglutinin of one of these pharyngeal sera than either alone. For example, NP 40 serum, which was not completely exhausted by any single spinal strain, was treated with (1) a mixture of Group I suspensions, (2) a mixture of Group II, (3) a mixture of Group I and Group II. The suspensions, the same throughout, were standardised to $4 \mathrm{mg}$. per c.c., and the serum, diluted to $1: 50$, received exactly $2 \mathrm{mg}$. of the mixed cocci per c.c. In (1) and (2) the homologous agglutinin was reduced from $1: 800$ to $1: 400$, and in (3) to $1: 200$.

It may be recalled that the parameningococcus of Dopter, obtained at first from the naso-pharynx and later from the cerebro-spinal fluid of cases of meningitis, sometimes produced a serum which agglutinated both parameningococci and meningococci. Experiments quoted in Dr Eastwood's Report ${ }^{1}$ showed that parameningococcus serum saturated with meningococci lost its agglutinin for meningococci but retained its agglutinin for parameningococci; while the same serum, saturated with parameningococci, lost its agglutinin for parameningococci but retained its agglutinin for meningococci. If Group I is substituted for meningococcus and Group II for parameningococcus, Dopter and Pauron's results resemble those mentioned with the naso-pharyngeal serum, NP 43. In reports by Ellis and Arkwright ${ }^{2}$ the parameningococcus was identified with their Group II, but Gordon ${ }^{3}$ could not establish its identity with any of his types of meningococci. Dopter and Pauron divided their

1 Journ. of Hygiene, xv. p. 432.

2 Brit. Med. Journ., December 18th, 1915.

s Gordon and Murray (1915), Journ. Royal Army Med. Corps, xxv. 
seven strains of parameningococci into three groups by means of saturation tests, and they suggested that perhaps additional varieties might subsequently be found. I am of the opinion that the strains of parameningococci which Dopter found to produce agglutinins for both varieties are like the pharyngeal strains which are agglutinated by Group II sera and produce agglutinins for both Group I and Group II. They differ from the commoner examples of cerebro-spinal meningococci in being less well-defined in relation to the two main groups.

\section{Variability of strains.}

In the course of this investigation some instances of variation have been observed which are of importance in their bearing on the position occupied by the less typical strains in the whole group of meningococci. For the most part, excepting variations in agglutinability and minor alterations in absorptive capacity, the various strains under observation have retained in culture their particular serological characteristics. This is not necessarily proof that they remain unvaried, since the method by which the cultures are maintained, i.e. by the transference of considerable quantities from one tube to another, may not bring to light possible modifications. As it is not to be expected that the culture would vary en masse, variations of individual cocci might occur but be overgrown by the predominant organism. Consequently their demonstration demands that individual cocci should be isolated from the general mass of the culture.

An experiment with that object has been made with M 17 culture. This particular strain was chosen because a change was observed in its absorptive capacity towards its own serum. Originally $2 \mathrm{mg}$. of culture per c.c. of 1-50 serum was sufficient to reduce the agglutinating power of the serum below $1: 100$, but later it was necessary to use much larger amounts to bring about the same result. I therefore endeavoured to ascertain whether all the individual cocci in the culture were identical, the idea having suggested itself that the presence of some with diminished absorptive capacity might account for the necessity of using increased quantities of culture to effect absorption. M 17 was plated and 40 single colonies were grown in subculture. Each of these was used separately to exhaust M 17 serum, and one strain only was found which failed to absorb the agglutinin for the whole culture while removing the agglutinin for itself. The other 39 strains removed the agglutinin for themselves and for the whole culture. The aberrant strain, after remaining in subculture for some time, was again plated. 


\section{F. GRIFFITH}

Four single colony strains were grown; three removed the whole agglutinin and one failed. Either the single colony first selected was not from a single organism or a certain number had reverted to the predominant type. The last non-absorbing strain, designated M $17 \mathrm{~K}$, was subcultured twice and again plated. Twelve single colonies were grown in subculture.

\section{TABLE XXII.}

Agghtination and absorption test of $M 17$ serum with $M 17$ (whole culture) and twelve single-colony strains of $M 17$. Serum before absorption titrated and tested on each strain, and after absorption again on each strain and on the whole culture.

Method. Three successive additions to 2 c.c. of 1 in 50 serum: (1) 5-10 mg. of each culture, (2) growth from whole tube two hours later; after centrifuging the clear fluid was pipetted off and (3) growth from a whole tube was again added.

\begin{tabular}{|c|c|c|c|c|c|c|c|c|c|c|c|c|c|c|}
\hline & \multicolumn{4}{|c|}{ Before absorption } & & & \multicolumn{4}{|c|}{ After absorption } & \\
\hline & & & & \multicolumn{4}{|c|}{$v$. absorbing strain } & \multicolumn{5}{|c|}{ v. M 17 whole culture } & \multicolumn{2}{|c|}{$\begin{array}{l}\text { v. absorbin } \\
\text { strain }\end{array}$} \\
\hline & & & & 20 & 400 & 800 & 1600 & 100 & 200 & 400 & 800 & 1600 & 100 & 200 \\
\hline $17(\mathrm{w}$ & iol & cultur & & $\cdot+$ & + & + & + & - & - & - & - & - & - & - \\
\hline M $17 \mathrm{~A}$ & & . & . & + & + & \pm & - & + & + & + & tr. & - & - & - \\
\hline 17 & & . & & + & + & \pm & - & + & + & + & + & - & - & - \\
\hline$[17 \mathrm{c}$ & . & . & . & . & + & + & tr. & + & + & + & tr. & - & - & - \\
\hline$[17 \mathrm{D}$ & . & . & . & . & + & + & tr. & + & + & + & \pm & - & - & - \\
\hline M $17 \mathrm{E}$ & . & . & . & . + & + & \pm & - & + & + & + & \pm & - & - & - \\
\hline M $17 \mathrm{~F}$ & . & . & . &.+ & + & + & tr. & + & + & + & + & tr. & - & - \\
\hline $17 \mathrm{G}$ & . & . & . & $\cdot+$ & + & + & tr. & + & + & + & \pm & - & - & - \\
\hline М $17 \mathrm{H}$ & . & . & . & + & + & + & - & + & + & + & \pm & tr. & tr. & - \\
\hline M 17 I & . & . & . & + & + & + & - & + & + & + & \pm & - & - & - \\
\hline $17 \mathrm{~J}$ & . & . & . & + & + & + & tr. & + & + & + & \pm & - & tr. & - \\
\hline $17 \mathrm{~L}$ & . & . & . & . + & + & + & tr. & + & + & + & + & tr. & tr. & - \\
\hline M $17 \mathrm{M}$ & & . & . & . + & + & + & tr. & + & + & + & + & \pm & - & - \\
\hline
\end{tabular}

Table XXII gives the agglutination results with each of these 12 single-colony strains, and demonstrates the absorptive capacity for their own and the homologous agglutinins in M 17 serum. It will be seen that the severe method of absorption adopted ensures the elimination of mere quantitive differences in absorptive capacity. The whole culture absorbed all the agglutinin for itself, but the single-colony strains, while absorbing completely their own agglutinins, only reduced in some cases very slightly the agglutinin for the whole culture. In 
simple agglutination the single-colony strains generally reached half the titre of M 17 serum for the whole culture. In this respect they resembled some of the pharyngeal strains previously mentioned which reduced the homologous agglutinin of M 17 serum but failed to exhaust it.

An absorption experiment was carried out with the object of ascertaining whether the agglutinin for the variant of M 17 could be more readily removed from $M 17$ serum by these pharyngeal strains than the whole agglutinin. In Table XXIII M 17 serum was absorbed with six pharyngeal strains; three spinal strains which do not absorb B agglutinin were included as controls. It will be seen that the agglutinin for the variant, $\mathrm{M} 17 \mathrm{~K}$, is more readily absorbed by five pharyngeal strains than the whole agglutinin. NP 2, which was shown to absorb M 16 serum, and the three spinal strains had practically no effect. The test suspension of M $17 \mathrm{~K}$ was composed of a mixture of the 12 daughter strains (Table XXII) and did not agglutinate as well as most of the individual cultures.

\section{TABLE XXIII.}

$M 17$ serum absorbed with spinal and pharyngeal strains. Serum titrated before and after absorption and tested on $M 17$ (whole culture) and on $M 17 K$ (variant).

Method. Equal parts of $20 \mathrm{mg}$. suspensions and 1 in 50 serum.

\begin{tabular}{|c|c|c|c|c|c|c|c|c|}
\hline \multirow{2}{*}{\multicolumn{2}{|c|}{ Absorbing Strain }} & \multicolumn{4}{|c|}{ Test on M 17} & \multicolumn{3}{|c|}{ Test on $M 17 \mathrm{~K}$} \\
\hline & & n 200 & 400 & 800 & 1600 & 200 & 400 & 800 \\
\hline Nil & . & + & + & + & + & + & + & \\
\hline NP 2 & . & + & + & + & \pm & + & + & \\
\hline NP 3 & . & . + & + & + & + & - & - & \\
\hline NP 5. & . & + & + & + & + & - & - & - \\
\hline NP 14. & . & . + & + & \pm & tr. & tr. & - & \\
\hline NP 67. & . & + & \pm & \pm & - & - & - & \\
\hline NP 86. & . & + & + & tr. & - & tr. & - & \\
\hline M9. & . & + & + & \pm & - & t & + & - \\
\hline M 48 . & . & t & + & + & tr. & + & + & - \\
\hline M 42 . & . & . + & + & + & \pm & + & + & \\
\hline
\end{tabular}

In Table XXIV the culture used to test the result of absorption was from $\mathrm{M} 17 \mathrm{~K}$ before the last plating, and agglutinated better than the whole culture. Certain pharyngeal strains have exhausted the serum of the agglutinin for the variant but not for the whole culture. In addition, two strains, NP 5 and NP 65, have reduced the agglutinin for the whole culture to below 1-200. This shows the effect of repeated additions of 
culture in increasing the amount of absorption. Much larger quantities of these two cultures were less effective in a single or even in two applications.

\section{TABLE XXIV.}

$M 17$ serum absorbed with nine naso-pharyngeal strains. Serum titrated before and after absorption and tested on $M 17$ (whole culture) and on $M 17 K$ (variant).

Method. Unheated suspensions of $20 \mathrm{mg}$. per c.c. added to 1 in 10 serum at intervals until final proportions were $19 \mathrm{mg}$. of culture per c.c. of 1 in 100 serum.

\begin{tabular}{|c|c|c|c|c|c|c|c|}
\hline \multirow{2}{*}{\multicolumn{2}{|c|}{ Absorbing Strain }} & \multicolumn{3}{|c|}{$\begin{array}{l}\text { Test on M } 17 \\
\text { (whole culture) }\end{array}$} & \multicolumn{3}{|c|}{ Test on M $17 \mathrm{~K}$} \\
\hline & & 200 & 400 & 800 & 200 & 400 & 800 \\
\hline Nil . & .. & + & + & tr. & + & + & + \\
\hline M 17 & . & - & - & - & - & - & - \\
\hline NP 4 & . & + & tr. & - & - & - & - \\
\hline NP 5 . & . & - & - & - & - & - & - \\
\hline NP 11. & . & + & \pm & - & tr. & - & - \\
\hline NP 17. & . & + & tr. & - & - & - & - \\
\hline NP 65. & . & tr. & - & - & - & - & - \\
\hline NP 67. & . & + & tr. & - & - & - & - \\
\hline NP 71. & . & + & tr. & - & - & - & - \\
\hline NP 77. & . & + & \pm & - & + & + & tr. \\
\hline NP 86. & . & + & \pm & - & - & - & - \\
\hline
\end{tabular}

To sum up, these results show that the variant of the strain M 17 shows the same capacity for absorbing an agglutinin in M 17 serum as do the pharyngeal strains, NP $3,4,5,11,17,65,67,71$ and 86 , and that this agglutinin is different from the predominating agglutinin for the original M 17 since these pharyngeal strains do not remove the latter.

The following variations were observed incidentally in other strains.

A strain of M 6, already referred to, was obtained which had completely lost its early features, namely, the agglutinability towards M 1 serum and the capacity to absorb the agglutinin. On returning to earlier stock cultures on egg, it was found that these had undergone no change. As this is an isolated example of so marked an alteration, I merely record it.

M 16 at first absorbed partially Group I sera (A agglutinin). Later, as shown, it failed to absorb.

M 43, as related in another place, was resolved into two components; when combined these exhausted the serum produced by the whole culture, though each separately removed only a portion of the agglutinin.

M 12 showed a marked quantitative alteration in absorptive capacity 
towards M 17 serum. At first $2 \mathrm{mg}$. of culture in the form of a heated suspension exhausted 1 c.c. of 1-50 dilution. Later two and a half tubes of fresh culture were added to 4 c.c. of 1-50, and the absorbed serum was tested on M 12, the absorbing strain, and on M 17 , the homologous. The reduction for the latter was from 1-800 to 1-400. To the 3 c.c. of serum remaining two more tubes of $M 12$ culture were added; agglutination of M 12 still occurred. After this second absorption the test on the absorbing strain and on the homologous culture showed that the serum was exhausted. The change in quantity of culture required for absorption of agglutinin for M 12 itself may be explained by the culture being hypersensitive, although it did not agglutinate with normal rabbit serum in $1-25$.

M 41 became towards M 10 serum similarly hypersensitive though not auto-agglutinating, and a large quantity of culture was required to remove the agglutinin for itself.

The above alterations in absorptive capacity of M 12 and M 41 recall the alteration in $M 17$ which led to the discovery of a variant differing qualitatively in absorptive capacity from the whole culture. Reference has been made in a previous part of this report to the possibility of slight differences in structure between two antigens so influencing the combining qualities of the agglutinins they produce as to lead to an apparently great divergence in the serological reactions of the strains containing them. There is little doubt that if a serum had been prepared with the variant of M 17 the whole culture of M 17 would have absorbed the homologous agglutinin, in consequence of the presence therein of the variant. In that case the relationship, for example, of NP 40 to M 15 would have been reproduced. That is to say, NP 40 (cf. M 17) would absorb the homologous agglutinin of M 15 (cf. M $17 \mathrm{~K}$ ) serum, but M 15 (cf. M $17 \mathrm{~K}$ ) would be unable to absorb the homologous agglutinin of NP 40 (cf. M 17) serum.

A few of the many examples of this relationship between two strains may be recapitulated:

M 15 absorbed NP 41 serum, but NP 41 could not completely absorb M 15 serum.

M. 17 absorbed NP 11 serum, but NP 11 could not completely absorb M 17 serum.

M 10 absorbed M 15 serum, but M 15 could not completely absorh M 10 serum.

M 43 absorbed M 17 serum, but M 17 could not completely absorb M 43 serum. 
These observations were referred to in suggesting an explanation for an anomalous result in connection with the absorption of the three agglutinins of Group I (pp. 149-50). It was found that M 10 and M 12 absorbed the homologous agglutinin from M 15 serum, i.e. C agglutinin, but M 12 could not absorb the agglutinin contained in M 10 serum, which agglutinated M 15. Those portions of the antigenic substances in M 10 and M 12 which combine with the agglutinin for M 15 may be assumed to stand in the same relation to each other as the antigens in M 17 and M $17 \mathrm{~K}$.

\section{Serological Characters of Spinal Strains in Relation to Age of Patient.}

Information concerning the ages of the meningitis patients, from whom the 66 spinal strains under investigation have been obtained, was a vailable in the case of 55 strains.

$\begin{array}{llcccc} & & \text { Total } & \text { Group I Group II } \\ \text { Patients under } 12 \text { years } & \ldots & 38 & 15 & 23 \\ \text { Patients over } 12 \text { years ... } & \ldots & 17 & 10 & 7\end{array}$

In the 15 Group I strains from children under 12 years are included the two aberrant strains, M 16 and M 46 .

Although the data are insufficient for any general conclusion to be drawn from them, there is evidently a definite preponderance of Group II strains over the commoner varieties of Group $I$ in a series of strains obtained from meningitis in children under 12 years. In patients over 12 , on the other hand, the Group I strains are found rather more frequently.

The disproportion is more marked in infants; of 14 cases under 1 year (included in the above 38) 10 yielded Group II strains and 4 Group I (including one aberrant strain). A similar though even greater preponderance of Group II was found in the naso-pharyngeal series of meningococci from persons of all ages. Thus the meningococci found in the cerebro-spinal fluid of meningitis in the most susceptible individuals tend to approximate in character to those in the naso-pharynx of the general population.

\section{Claassification of Meningococci by Serological Tests.}

This investigation of cerebro-spinal and naso-pharyngeal meningococci has shown that there is no group of naso-pharyngeal cocci which, though identical morphologically and culturally with meningococci, possesses specifically distinct serological characters. 
Considering the results of the tests upon the whole series, it has been found that agglutinating sera prepared with certain spinal strains divide the greater part of the series into two groups, the remaining strains being less well defined, both in agglutinability and absorptive capacity, in relation to these two groups. The strains which fail to conform to the division into groups are more frequently of naso-pharyngeal than of cerebro-spinal origin.

On examining my results in relation to the age of the patients, I find that meningococcal strains obtained from young subjects, particularly infants, but also in the case of older children, resemble the naso-pharyngeal strains of non-contacts in two respects: (1) they yield a higher proportion which is not amenable to group differentiation than do the strains obtained from the disease in adults; (2) they also yield a higher proportion of Group II strains compared with adults. It is quite possible that the more virulent meningococci, i.e. the strains usually found responsible for the disease in the older and less susceptible elements of the population, are those which conform fully to the two main groups in serological characters, and that divergence from these characters is correlated with less virulence, i.e. feebler capacity for invading the system from the naso-pharynx.

But apart from the above broad distinction there has not been shown any possibility of estimating degrees of virulence from serological reactions, and the question is complicated by the differences in individual susceptibility.

It has been found by Gordon, who obtained his material mainly from the military population, that the serological characters of his spinal strains showed uniformity of type. This difference in the source of material may, to some extent, explain why his results do not agree with mine. The cerebro-spinal strains studied in my report have been obtained almost entirely from the civil population and include a large proportion from cases of meningitis in children.

Two instances given in the present report of cultures obtained from post-basal meningitis in infants may be mentioned in illustration. They showed as marked divergence in serological characters from the two main groups as any strain from the naso-pharyngeal series. Both strains agglutinated slightly with sera of Group II; one, M 46, produced a serum which agglutinated mainly Group I strains and the other, M 55, a serum which influenced only itself to any extent. I hope to show later the position in relation to the two main groups occupied by these strains which differ serologically from the commoner and presumably more virulent spinal strains.

In this connection, as showing that the possibility of these differences existing had been recognised, the Report of the Special Advisory Committee ${ }^{1}$ may be quoted.

1 Medical Research Committee. Report upon Bacteriological Studies of Cerebro-spinal Fever during the Epidemic of 1915. 
"It must be observed, however, that the strains studied have been epidemic strains from the meninges. It is possible that the meningococei found in the posterior basic meningitis of infants in non-epidemic times will prove to belong to other types and the same seems likely to be true of many of the meningococci found in carriers." The Medical Research Committee's Report says further, with regard to the influence of age on the incidence of the disease: "It is well known that the sporadic form of cerebro-spinal fever as seen amongst the civilian population is mainly a disease of infancy and early childhood. It becomes rarer in adolescence and is uncommon in adults."

The above expression of opinion was foreshadowed by Arkwright ${ }^{1}$ in 1909, as the following quotation shows. "One feature of the group of meningococci from sporadic cases taken as a whole appears to be that its members are more frequently found to deviate from the type to which most strains conform than is the case with the epidemic group."

Differences in susceptibility may account for the discovery of strains from meningitis in adults which would be classed on the above principles amongst the least virulent. Such strains however have been relatively uncommon, and it is evident that criteria for the identification of the meningococcus which are based on the serological reactions of meningococci occurring most frequently in adults may exclude strains capable of causing meningitis in children.

The adoption of excessively rigorous standards, which can perhaps be justified as a measure of control in the early stages of an outbreak of cerebro-spinal fever, may explain why Gordon and his fellow-workers ${ }^{2}$ have classified the Gram-negative cocci of the naso-pharynx in a way which $I$ am unable to regard as correct.

The general consensus of opinion is in agreement with the above statement that the meningococci concerned in the recent prevalence of cerebro-spinal fever show a well-marked differentiation by simple agglutination tests into two main groups, a variable number remaining which cannot definitely be placed.

Gordon, however, claims to demonstrate four specific types by means of absorption tests, but differences in absorptive capacity, however well marked, cannot in themselves be taken to be proof of specific differences. I have been able to show that two strains from the same culture may exhibit differences in absorptive capacity which would, according to Gordon's method of classification, resolve them into separate species. Gordon indeed recognises an affinity between his Types 1 and 3, and more recently between Types 2 and 4 also, and in his final conclusion states that it must not be assumed that the limit of their individual variation has yet been defined. Possibly he will discover a still closer relationship in the future. In one of his earlier

1 Journ. of Hygiene, IX.

a Bacteriological Studies, etc. Medical Research Committee, Special Report Series, No. 3. 
reports ${ }^{1}$ he mentions that a strain absorbed the specific agglutinin from sera of Types 1 and 3 and was therefore labelled amphoteric. It seems to me impossible to justify the specific differentiation of two varieties thus linked together.

Reference should also be made to the work of Colebrook and Tanner ${ }^{2}$ who have discussed the carrier problem and have come to the conclusion that most carrier strains are true meningococei. In considering their reasons for adopting this view they discuss two hypotheses to account for the apparent inability of the majority of such strains to determine general infections: (1) most carriers and normal persons possess an adequate natural immunity against the meningococcus, (2) the pharyngeal coccus of the carrier is an attenuated strain incapable of determining a meningitis. While not coming to any final conclusion as to which of the alternative hypotheses is preferable, they apparently consider attenuation of virulence to be an important factor.

A study of the agglutinogenic properties of these irregular and apparently less virulent strains has shown that the sera prepared from certain of them pick out other members of the class in an irregular fashion, and that therefore these strains are not all identical in antigenic capacities. Such sera agglutinate also the presumably more virulent strains which conform to the reactions of the two main groups, thus demonstrating that the strains producing them are antigenically related to the latter. They agglutinate however strains in both groups more or less equally, a result which apparently invalidates the grouping obtained with the standard spinal sera.

Evidently therefore there is some difference between the Group I and II antigens contained in the typical strains and the related antigens in the less well defined strains, e.g. the latter may not be affected by an antibody in the sera of the former but nevertheless produce antibodies which have a marked action upon corresponding antigens in the former.

Analogous differences, not revealed by simple agglutination tests, have been demonstrated between the antigens of the typical Group I strains and also between those of Group II. For example, two antigens may combine with, i.e. absorb, the same agglutinin though one antigen does not combine with the agglutinin produced by the other.

When it is recalled that variations in antigenic capacity of a similar nature may occur in a strain during sub-cultivation, it is reasonable to assume that the meningococcus antigens are not precisely fixed or stable substances, but are liable to modification under the influence of environment.

I regard therefore these cerebro-spinal and naso-pharyngeal strains which I have investigated as forming a single species, the meningococcus

1 Identification of the Meningococcus. Journ. Royal Army Med. Corps, October, 1915.

2 Journ. Royal Army Med. Corps, January, 1916. 
species, which includes two well defined serological races linked together by less highly differentiated strains. This tendency for a bacterial species to differentiate itself into races may be regarded as a continuation of the same evolutionary process whereby bacteria with the characteristics of a common genus exhibit emergence into a greater or smaller number of species.

The views expressed by Andrewes and Horder (Lancet, 1906, II 711), on the classification of organisms into different species may be usefully applied to racial differences between different strains of meningococci.

"When an arbitrary set of characters is taken as a basis for the classification of a group of natural objects the same phenomena are usually seen-large groups of like objects connected by small groups which differ from them in one or two particulars. If the numerical frequency of each individual like group is represented by the proportional height of a vertical line and the lines are arranged in series, the commoner types stand out boldly above the rarer ones. Only in nature they are plotted out, not in linear series, but in space of two dimensions, as it were, so that the common types stand out as mountain tops above their fellows, each mountain connected by valleys of intermediate types with many of its neighbours. If now the mountains were cut off by a horizontal plane half-way up their sides and attention were paid only to the mountain tops, disregarding the valleys, we should have the popular conception of species."

Similarly in the two series of meningococcal strains the two serological groups stand out above the mass of undifferentiated strains.

As mentioned above, these two groups are not fixed types but may be further sub-divided by means of absorption tests into sub-groups which are probably "centres of variation" in the different stages of evolution of the meningococcus antigens. Such variations in the serological properties of antigens must ultimately depend upon changes in their chemical constitution.

Andrewes (1913), in his Presidential Address, The Nature and Degree of Specific Differences amongst Bacteria', discussing the importance of chemical evolution in determining the formation of bacterial species, says: "Only now do we begin to get a hint of what I believe to have formed a large part of the course of evolution within the morphological boundaries of bacterial genera-namely, that it has been a chemical rather than a structural one-a change not so much in the configuration of the organism as in that of the protein molecules which build it up." (This conception can, I think, be applied to the evolution of racial types within a species just as much as to the evolution of different species.) "But just as in the building up of higher organisms many proteins are concerned so, though perhaps in a lesser degree of complexity, must the bacterial body be built up of several kinds of protein, in varying combination, some perhaps peculiar to the species others common to many."

1 Proc. Royal Soc. Medicine, vr. (Pathological Section).

Journ of Hyg. xvir 
And with reference to racial differences of meningococei the Medical Research Committee's Report says: "The races are defined by methods the relative values of which may still be disputed and the differences brought out by these methods may be conjectured to depend upon slight changes in the atom groupings of the bacterial protein determining its reaction with a particular antibody."

Although the validity of the sub-division of the two main groups of meningococci into types upon the results of absorption tests is open to question, there is no doubt as to the importance of such serological tests in furnishing information on the relationship of antigens in different strains. The possibility of the differences in antigenic capacity being correlated with differences in virulence makes their detailed study of more than academic interest.

My observations on the serological and biochemical reactions of the meningococcus have brought me to the conclusion that the meningococcus antigen is composed of two different proteins and it is the relative proportions of these in one strain which decide its position in relation to the two main groups. The further division into sub-groups and atypical strains must on this hypothesis be due to alterations in the configuration of the two specific proteins.

It is probable that the changes in the atom groupings are not haphazard but follow a definite tendency. My results seem to show that in the case of the meningococcus antigens they are in the direction of increased or diminished complexity of structure of the receptor apparatus, with corresponding increase or diminution in the range of combining capacity. This inference is based upon a comparison of the absorptive capacities of strains for the agglutinins contained in different sera.

In the annexed scheme, which is intended to represent graphically evolution of antigenic complexity, I have commenced with a hypothetical complete meningococcus antigen possessing the full antigenic capacities of Group I and Group II.

The actual existence of such strains has not been demonstrated but is at least suggested by the following considerations. In the severe epidemic of cerebro-spinal fever in Silesia during the winter of 1904-1905, the strains of meningococci tested by Lingelsheim all reacted with monovalent agglutinating sera prepared with one of them. The majority of the strains were cultures from the naso-pharynx. It may be argued that Lingelsheim was dealing with only one of the two groups. Against this are his observations that all his strains produced strong and equal fermentation with dextrose and maltose contained in his solid media. There is certainly a possibility, though at the present day no final conclusion can be reached, that his strains each possessed the complete antigenic properties of both groups. It is of interest to note that in subsequent German investigations during the years 1906-1909 (see Dr 


\section{F. GRIFFith}

Eastwood's Report ${ }^{1}$ ) cerebro-spinal strains were found which exhibited less uniformity in agglutination and fermentation reactions; also aberrant strains were found in the naso-pharynx. It is possible that strains with double antigenic properties such as Lingelsheim may have been dealing with were relatively unstable and capable of being easily resolved into two less complex components with one or other antigen in predominance. An observation by Dr Scott may be quoted in this connection; he obtained from a single culture two strains, one with Group I characters and the other with Group II.

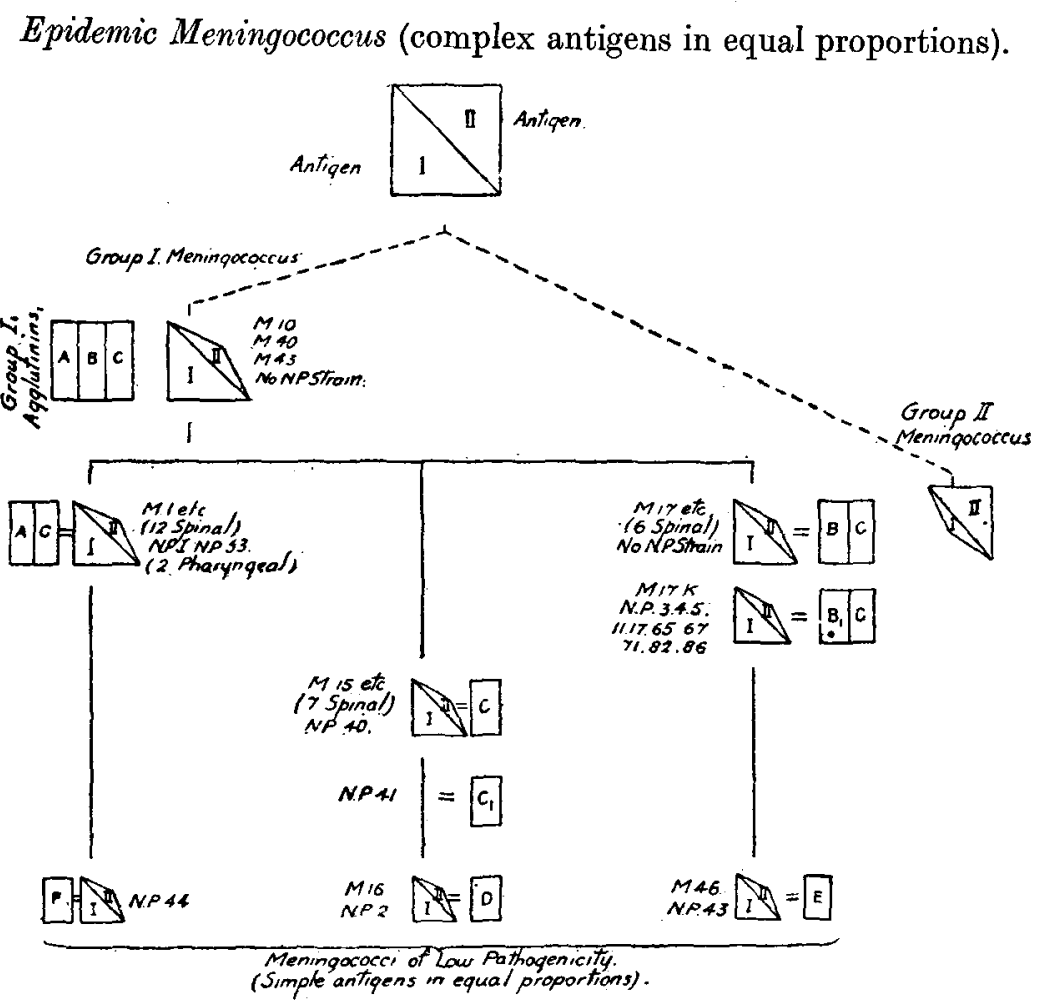

In their bearing on this question the results of Walker Hall and Peters ${ }^{2}$ are also suggestive. They adopted the plan of comparing the serological reactions of meningococci obtained from the same patient on successive days. In two cases of severe cerebro-spinal fever they found differences. The second of these, recorded at the end of their report, may be quoted as an example. The meningococcus recovered from the cerebro-spinal fluid on the third day absorbed Type 2 agglutinins, while

1 Journ. of Hygiene, xv. 405.

2 Changes in the Agglutinability, Fermentation Reactions and Absorptive Capacities of the Meningococcus during the Acute Attack. Journ. Royal Army Med. Corps, October, 1916. 
that recovered on the fourth day absorbed agglutinins of both Types 1 and 2. It might be suggested that the injection of Dopter's serum after the first withdrawal of fluid had some influence in producing this apparent alteration. Assuming the presence of two components in the spinal fluid, Dopter's serum would reduce the Type 2 cocci and there would be increased probability of isolating a strain containing Type 1 cocci. The work of these authors is of particular interest to me in furnishing as it does some experimental evidence of a virulent strain with double antigenic properties, and I agree with them that "some aspects of the problems associated with the grouping of meningococci may be solved by further study on similar lines."

But, though possibly with rare exceptions, the antigens of the strains found in the present epidemic were less complex and commonly showed a preponderance of $\mathrm{I}$ or of $\mathrm{II}$; these are figured in the scheme as descendants of the primary antigens.

A particular study was made of spinal strains containing Group I antigen and related strains from the naso-pharynx, and I have attempted to represent in the remainder of the scheme the plan upon which these various strains appear to be linked together.

Following the genealogical table downwards, a triangle represents the antigen and an oblong the agglutinin with which it is capable of combining, and diminution in complexity of these substances is indicated by decrease in size of the figures. Thus the three most complex antigens of Group I are contained in M 10, 40 and 43, which can bind all three agglutinins $\mathrm{A}, \mathrm{B}$ and $\mathrm{C}$ of Group $\mathrm{I}$; no strain of equal complexity was found in the naso-pharynx. One of these complex strains, M 43, was resolved into two daughter strains, equivalent respectively in serological characteristics to M 1 and M 17; each of them was capable of binding two agglutinins but neither was of sufficient antigenic complexity to bind all three.

Comparing spinal with pharyngeal strains, two pharyngeal strains were found which absorbed the two agglutinins $A$ and $C$, but none was quite equal to $\mathrm{M} 17$ in absorbing $\mathrm{B}$ and $\mathrm{C}$ agglutinins. There were seven spinal strains and one pharyngeal strain of still simpler antigenic structure which combined only with $\mathrm{C}$ agglutinin.

According to Andrewes and Horder's simile, these three sub-groups of Group I, of which M 1, 15 and 17 are types, would stand out as mountain tops united in the valleys by the undifferentiated spinal and pharyngeal strains such as M 16 and 46, and NP 2, 43 and 44, which can only with difficulty be identified with any other strain. These intermediate types in the valleys, to use their words, illustrate variation and the connection between allied species (here serological races). 
The analysis of Group I antigen, and the demonstration of its association with Group II, serve to explain (a) different range of valency of different Group I sera and $(b)$ action of naso-pharyngeal sera on cerebrospinal strains, in the following way.

I have represented in the scheme every strain as containing a small portion of Group II antigen in addition to the main antigen of Group I. It will be seen that in the undifferentiated strains the two antigenic substances become proportionately equal and the Group II portion has become of greater relative importance than in the more complex strains. This relationship is reflected in their antigenic capacities, since many produce sera which agglutinate more or less equally strains in the two well defined groups. These latter strains, although they may be well agglutinated by such naso-pharyngeal sera, do not readily absorb the homologous agglutinins, and it has been observed that a mixture of strains of the two groups may be more efficacious in absorbing than strains of either group alone. In the case of the more complex strains on the other hand, e.g. M 10 and M 43, the Group II antigen is quantitatively of slight importance, and in the process of immunisation the antibodies are produced against the most prominent antigen. Thus one obtains a serum the agglutinating action of which is largely confined to those strains containing mainly Group I antigen.

In regard to the production of acid in the presence of glucose and maltose it has been found that strains which produce agglutinins mainly of one group generally produce more acid with one sugar than with the other; the fermentation of glucose is associated with the formation of Group II agglutinins, and the fermentation of maltose with the agglutinins of Group I. On the other hand the atypical strains, which have been assumed to contain a simple form of each antigen in about the same relative proportions, often ferment both sugars equally. It has been observed that the latter strains adapt themselves with greater difficulty than the typical strains to growing on glucose agar without added serum.

Following the genealogical table from below upwards and adapting the above considerations to Andrewes and Horder's hypothesis, the sub-groups of Group I, as well as the less well defined Group II, would be types emerging from a mass of undifferentiated forms, and they would owe their greater frequency of occurrence in cerebro-spinal fluid to being more fitted for invasion by chemical adaptation. This adaptation is represented as due to progressive increase in complexity of structure and $I$ have indicated that this progression may be continued until a strain is evolved which is equally well equipped with the complete Group I and Group II receptors. This I have shown by figuring a 
hypothetical strain in which both the meningococcus antigens are in equal proportions and of maximum complexity. The introduction into the community, from within or without, of a strain approximating to such a prototype might explain the origin of an epidemic of cerebrospinal fever.

An epidemic meningococcus of such high complexity would not be stable but would undergo degeneration with rapidity proportional to the resistance it met and would retrace its steps along the path of evolution, giving rise on the way to the two main groups and to the various sub-groups of diminishing complexity. It would end again where it arose in the mass of undifferentiated forms with relatively slight capacity for invading the body from their habitat in the nasopharynx.

There are thus two conceptions, (1) the slow upward development of complex virulent types, (2) the more rapid devolution or degeneration into simple less virulent types. Both of these processes are likely to take place in the course of an epidemic and may to some extent go on simultaneously.

It will be of interest to examine the evidence available of the serological characters of the meningococci obtained in the early period of the epidemic on Salisbury Plain. Ellis $(1915)^{1}$ found his Type 1 eight times and Type 2 three times. Arkwright $(1915)^{1}$ reported on nine cases from the First Canadian Contingent on Salisbury Plain; five belonged to the "meningococcus" group and two to the "parameningococcus" group (the former corresponds to Type 1 of Ellis and Group I of this report); one, Chandler, agglutinated slightly with sera of both groups and the remaining strain, Chase, fell in different groups on two occasions. Arkwright concluded that Chandler probably belonged to his meningococcus group and that Chase perhaps contained individual cocei which reacted with different sera. Gordon $(1915)^{2}$, working with 32 strains from various sources, classified 23 in Types 1 and 3 (apparently related in simple agglutinability and probably corresponding to Group I of this report) and 8 in Type 2, the remaining one not conforming to any of the three types.

It is clear that the two serological races were already well defined early in 1915, and there seems little doubt that strains containing Group I antigen were most conspicuous at the commencement of the epidemic. If the results recorded in this report, which deals with strains collected at a later stage of the outbreak, are contrasted with the above, it will be seen that meningococci of Group II have been obtained from the cerebro-spinal fluid rather more frequently than those of Group I. The various strains investigated were obtained from different parts of the

1 Brit. Med. Journ., II. 881 and 885.

2 Gordon and Murray. Journ. Royal Army Med. Corps, xxv. 411. 
country and their collection was not begun until towards the end of March, 1915.

My strains include many from cases of meningitis in children, and the results are therefore not strictly comparable with those quoted above. The experience of the workers for the military authorities has however been similar, as the following quotation from Lieutenant-Colonel Gordon's report" shows: "The meningococci coming from military cases during 1915 were chiefly specimens of type 1 at first, but as the outbreak progressed, type 2 became more abundant. When the disease declined, during the summer of 1915 , several specimens of type 3 were met with; and the solitary specimen of type 4 also dated from the later stages of this 1915 outbreak. It was noteworthy that when the disease returned in the last months of 1915 , first of all type 1 reappeared, to be shortly succeeded by type 2 , which then became the predominant type. The epidemic of 1916, however, has also been remarkable for an increase in the number of cases due to type 4."

Gordon summarises the meningococci from cases during 1916 as follows:

$\begin{array}{lrrrr}\text { Type } \quad \ldots & 1 & 2 & 3 & 4 \\ \text { Specimens } & 64 & 69 & 6 & 18\end{array}$

In comment on the above summary, I may point out that types 1 and 3 give a total of 70, and types 2 and 4 a total of 87 . The former, 70 specimens, I regard as Group I, and the latter, 87 specimens, as Group II.

Apparently the meningococci responsible for sporadic cases and small outbreaks prior to the year 1914 were not so well defined in their serological characters as those obtained subsequently.

In reference to the epidemic of 1914-1915, the Medical Research Committee's Report says: "The reports from the Salisbury Plain area suggest not indeed that the Canadians imported a new disease into this country, for we have always had it with us in sporadic form, but that they did introduce a virulent strain of meningococcus and were in some degree responsible for its spread."

If the results of recent serological work in this country are compared with past records, the above suggestion finds some support. Arkwright $(1909)^{2}$ foreshadowed the division of meningococei into serological groups but his groups were not well defined nor limited to two. In his work on the epidemic of 1915 on the other hand, he found that only 5 out of 35 spinal strains failed to conform to one or other of two groups. Ellis during the same period was similarly successful in allotting his strains to two groups, and the work in this laboratory had a like result. Gordon ${ }^{3}$ in his previous work on the agglutination reactions of the meningococcus (1907) failed to find them of any value in the identification of the meningococcus. But recently he, like the above authors, readily identified two main groups into which 80 per cent. of his spinal strains fell.

1 Special Report Series, No. 3, pp. 16-18.

2 Journ. of Hygiene, IX.

3 Report to the Local Government Bourd, 1907. 
It would be interesting to know if there had been a similar correlation between the types of meningococci in the naso-pharynx at these different periods.

There is unfortunately no information as regards the distribution of the meningococcus in the naso-pharynx of people in this country prior to the recent epidemic. Arkwright in his early investigation of contacts on Salisbury Plain did not find the meningococcus at all widespread: 4 positives out of 349 naso-pharyngeal examinations of contacts. The investigation of non-contacts conducted in the Board's Laboratory showed that during the month of April, 1915, meningococci were numerous in the throats of a section of the London population. Whether this result represented the normal seasonal incidence or was a special circumstance related to the epidemic prevalence cannot now be determined. As regards the serological characters of the pharyngeal meningococci of non-contacts, it has been found that the standard Group II sera agglutinate many more pharyngeal strains than the Group I sera and that the Group II antigens of the pharyngeal strains can be more readily identified with the similar antigens in the spinal strains than can the pharyngeal Group I antigens.

As an interesting parallel to the evolution of epidemic meningococci, the results of an investigation by Seligmann ${ }^{1}$ on the bacteriology of dysentery in the German army may be quoted. He observed that at the height of the disease in 1915 and again in the following year the strains of dysentery isolated were almost exclusively typical, and it was only towards the decline of the epidemic in each season that the atypical forms made their appearance. Discovering at the end of the epidemic of 1915 that carriers of dysentery bacilli were rare, he determined, on the recurrence of the disease in 1916, to study the strains from the very earliest cases. His assumption was that if epidemic strains developed anew under the influence of climatic and other factors, the earliest strains would include amongst them undeveloped intermediate forms. He tested the suspicious strains from the first 34 cases as to their relationship to dysentery bacilli, and he found a considerable number of these diverged more or less from the recognised types; of the remainder, five were readily classed as typical Shiga and nine as Flexner bacilli. The results supported his original hypothesis, and in addition he was able to arrange the strains in such a way as to give a strong impression of stages in the evolution of the types of dysentery bacilli. The series was as follows:

(1) A gas-forming bacillus related to $B$. coli.

(2) Inagglutinable bacilli of the Flexner group without appreciable antigenic properties.

1 Centralbl.f. Bakteriol. Orig. LxxIx. 71. 
(3) Poorly agglutinable Flexner bacilli, possessing highly specific and individual antigens.

(4) Poorly agglutinable Flexner strains, the antigenic capacities of which closely resembled the normal Flexner type.

(5) Typical Flexner bacilli.

(6) Strains (Doppelstämme) which were agglutinated by both Flexner and Shiga sera and produced specialised sera showing relationship to (4).

(7) Poorly agglutinable Shiga-Kruse strains.

(8) Typical Shiga-Kruse bacilli.

The author noted that there were many gaps, notably between Groups I and 2 and between Groups 6 and 7 .

There are certain analogous features in the serological reactions of meningococci and dysentery bacilli. In both species there are two welldefined groups and a number of strains which exhibit characteristics of both groups. In the case of the meningococcus some of the latter strains have not only the agglutinability of both groups but also the agglutinogenic capacities. Dysentery strains corresponding to these would occupy the gap between (6) and (7), in Seligmann's series.

It seems to me difficult to conceive the typical Flexner antigen changing into the typical Shiga antigen. I should prefer to consider the intermediate strains as possessing simple forms of both Shiga and Flexner antigens, one or other of which by a process of chemical adaptation may develop greater complexity. Evolution thus takes place along two different lines, resulting in the formation of typical bacilli eithar of the Shiga or of the Flexner type.

Two alternative explanations of emergence of types in connection with the recent epidemic of cerebro-spinal fever may be discussed.

(1) Emergence occurred in one focus only, with subsequent spread and confusion with indigenous strains. The suggestion that a virulent strain was introduced into the country has been referred to. According to the scheme on p. 177 this meningococcus might be represented either as approximating to the hypothetically complete epidemic strain with both antigens in equal proportions and of equal complexity or as a strain less completely equipped but with the Group I component more developed than the Group II. On the latter assumption this strain, being alterable in type, might in its passage from naso-pharynx to nasopharynx become resolved into two less complex strains, one with the Group I antigen in excess and the other with the Group II. The greater complexity of the former antigen would result in the greater range of variation which has been shown by strains of Group I. On the other hand the simpler form of Group II antigen would explain the occurrence of the large number of sub-groups in both the spinal and the naso- 
pharyngeal series of apparently equal complexity. The frequent occurrence of the typical Group I strains in the spinal fluid compared with their comparative rarity in the naso-pharynx would be accounted for on the assumption that they were more adapted for invading the body in virtue of the possession of the more highly developed antigen.

This higher virulence however, is only relative, as the following considerations show. Three of the more complex Group I strains were found in the naso-pharynx of the 700 non-contacts examined. Since the incidence of cerebro-spinal fever in 1915 was 07 per 1000 of the general population of England and Wales and approximately half the cases would be due to Group I strains, it is obvious that the most virulent strains produce cerebro-spinal fever in a very small minority of the persons carrying such organisms in their throats.

The above hypothesis carries with it the assumption that carrier strains of meningococci spread throughout the country from a primary focus on Salisbury Plain, and that the different serological races are less complex variants of the original epidemic strain. One difficulty in supporting this hypothesis is that the existence of this complex epidemic strain, though suggested, has not actually been demonstrated.

(2) Emergence occurred by evolution in more than one focus. The Medical Research Committee's Report discusses the conception that in an epidemic of cerebro-spinal fever there may be a saprophytic spread of individual races which have attained greater virulence side by side with the domestic and relatively harmless strains indigenous to the locality. In this case evolution takes place along different lines, and one has to imagine some influence in action which sets in motion the process at a number of foci.

In the earliest serological investigations made during this epidemic Ellis ${ }^{1}$ found both types represented in every epidemic focus he investigated and Arkwright ${ }^{1}$ found no support for the view that the meningococci concerned in a particular outbreak were limited to one group. Such distribution may indicate that the two types were evolved simultaneously in the several foci; it is however equally consistent with a possible spread of both from a single focus.

The final decision between (1) and (2) rests probably with epidemio$\log y$, but the above evidence brought forward on the variations in the serological characters of the organisms concerned may perhaps be of some assistance.

Further light may be thrown on these questions in the future when an epidemic occurs after a period during which the disease has only

1 Brit. Med. Journ., 1915, II. 
exhibited sporadic manifestations. In the meantime it will be interesting to study, as the present prevalence of cerebro-spinal fever gradually diminishes, the changes taking place in the serological characters of the strains of meningococci concerned. And, in the light of the evolutionary possibilities suggested by Seligmann in the case of dysentery bacilli and enunciated in more general terms by Andrewes and Horder, who consider that different species may still be in process of emergence from the same genus, one might speculate on the relationship to the meningococcus group of the naso-pharyngeal organism which cannot be accepted as a meningococcus but differs culturally from the true meningococcus only in the marked production of pigment. The few strains of this character which I examined exhibited no serological relationship to true meningococci. According to one's point of view, such strains might be considered as the possible starting point or the possible end point in the process of evolution of the meningococcus.

\section{SUMMARY AND CONCLUSIONS.}

The serological characters of 66 strains of meningococci obtained from the cerebro-spinal fluid in cases of meningitis have been studied. Serological tests of a similar nature have been applied to 86 strains of Gram-negative cocci, culturally identical with meningococci, obtained from the naso-pharynx of non-contacts. The two series have been compared in respect of agglutinability, agglutinogenic capacity, and absorptive capacity with the following results:

The majority of the spinal strains can be divided into two main groups by simple agglutination tests with selected spinal sera: about 27 can be assigned to Group I and 34 to Group II, the remaining five being relatively inagglutinable or equally agglutinated by sera of both groups.

If the naso-pharyngeal strains are grouped on the same principle, that is, according to the height of titre and consistency of reaction in the presence of the same standard group sera, two or three would be classed as Group I and about 50 as Group II; the remainder could not be classed on account of inagglutinability or equal agglutination with sera of both groups.

The naso-pharyngeal strains produce active agglutinating sera for spinal strains. Certain pharyngeal strains, resembling the atypical spinal strains in agglutinability and agglutinogenic capacity, produce sera which agglutinate without distinction spinal strains belonging to sepa 
rate groups as shown by their agglutination with the standard spinal sera.

The naso-pharyngeal and cerebro-spinal strains which are agglutinated by Group II sera absorb the homologous agglutinin from those sera with equal readiness. On the other hand, the typical Group I sera are less readily and completely absorbed by the pharyngeal than by the spinal strains agglutinated by them. This difference has been found to be dependent upon variations in complexity of structure of the Group I antigen. Similar variations have been shown to occur in typical spinal meningococci during subcultivation.

Stated in general terms, the inter-relationship between spinal and pharyngeal strains is as follows:

The naso-pharyngeal strains are not serologically separate and distinct from the cerebro-spinal strains, and moreover have not been found to exhibit among themselves such serological differences as would justify the separation of any number of them into a class or classes, identical with each other and distinct from meningococci of cerebrospinal origin. Consequently I can find no justification for the view that naso-pharyngeal meningococci of the non-contact differ as a class from strains which might be found within the immediate environment of cases of the disease. The occurrence of such organisms in considerable numbers among the non-contact population, though unexpected, is in accordance with epidemiological experience that the majority of cases of the disease cannot be traced to a previous focus.

The most pronounced of the serological differences which are found between spinal and pharyngeal strains are not greater in degree than the differences between individual spinal strains. Admittedly the meningococci of cerebro-spinal origin which exhibit so great divergence from the majority or the typical, are relatively few, but it is certain that the 66 specimens of cerebro-spinal origin investigated do not exhaust all the possibilities of variation. For this reason, as well as on account of the necessity of preparing an agglutinating serum from each atypical strain, it has not been possible to identify every naso-pharyngeal with a cerebro-spinal, that is, with a meningococcus of proved pathogenicity; but sufficient progress has been made to justify a general statement that the serological differences between the spinal and pharyngeal strains are not of a specific nature.

Although, as I have shown, the two series of meningococci belong to one and the same species, the comparative tests show that while a considerable number of the pharyngeal strains are serologically identical 
with the majority of the spinal strains, there is a residue in each of the two series, much larger in the case of the pharyngeal, which is not capable of being identified in a complete serological sense with that majority. These residual pharyngeal strains are not identical with each other, but a few of them have been identified with the smaller number of the residual spinal strains.

It may be concluded from the above that a certain proportion of pharyngeal meningococci appear to effect a successful invasion of the meninges with relative infrequency, and there is a reasonable probability that the differential factor is one of virulence. There is thus suggested a correlation between virulence and serological reactions. The serological differences between strains of meningococci have been shown to depend upon variations in complexity of antigens as inferred from differences in range of absorptive capacity. The least complex strains are found more frequently in the naso-pharynx of the non-contact and in the meningitis of infants than in cerebro-spinal fever of adults. It may be concluded that virulence, in the sense of capacity to invade the meninges from the naso-pharynx, runs parallel with antigenic complexity. The most complex strains are the most virulent and occur most frequently at the height of an epidemic.

The less complex antigens do not bind the anti-bodies produced by the more complex. This fact is of obvious practical importance in the selection of strains for the production of therapeutic sera; each of the two group antigens should be represented in the most complex form available.

The naso-pharyngeal strains of Gram-negative cocci used in this investigation were selected solely on the grounds of identity in cultural and fermentation tests with meningococci of cerebro-spinal origin. Since the serological tests have confirmed the relationship of the former organisms to the latter, the conclusion is justified that meningococci form a well-defined species of Gram-negative cocci and can be identified in the naso-pharynx by careful application of cultural and fermentation tests.

\section{ADDENDUM.}

Since the preparation of the preceding part of the report the serological reactions of a further series of 24 spinal strains have been tested. For seven of the cultures I am indebted to Professor Andrewes. The remaining cultures were obtained from cerebro-spinal fluid of cases of meningitis sent to the Board's Laboratory for diagnosis from various 
parts of the country during the period from February 28, 1917, to May 5, 1917. The same tests have been applied as were found useful in comparing the antigenic properties of different strains of meningococci in the main report. All the suspensions of the different strains were the same throughout. The results, which are summarised in the accompanying table, serve to illustrate several of the characteristic features of the inter-relationship between strains of meningococci demonstrated in the report. These will be referred to under the various headings.

A. Correlation between fermentation reactions and serological tests; the production of acid with maltose is associated with the presence of Group I antigen, and acid production with glucose with the presence of Group II antigen.

B. Division of spinal strains into two groups by the action of two agglutinating sera prepared with standard spinal strains, M 10 and M 18 .

Demarcation of spinal.strains into groups disappears when strains are tested with sera made from undifferentiated naso-pharyngeal strains, NP 44 and NP 43.

C. Group I strains exhibit gradation in antigenic complexity and corresponding variations in absorptive capacity for the agglutinins in Group I sera.

M 69 absorbs homologous agglutinin from three sera: M 10 serum (A agglutinin), M 17 serum (B agglutinin), and M 15 serum (C agglutinin).

$\mathrm{M} 67,68,70,71$ and 72 absorb $\mathrm{A}$ and $\mathrm{C}$ agglutinins.

$\mathrm{M} 76$ and 79 absorb $\mathrm{B}$ and $\mathrm{C}$ agglutinins.

$M 73,74,77,78$ and 75 absorb $C$ agglutinin only, the first four partially and the last, M 75, completely.

M 80 absorbs B agglutinin partially.

D. Group II strains do not show the same gradation in absorptive capacity as the Group I strains. The majority absorb one or other of the four selected Group II sera, but several, M 86, 87, 88 and 81 fail to absorb any agglutinin completely from these spinal sera.

E. Spinal strains in both groups may absorb agglutinin from the naso-pharyngeal serum, NP 44. 


\section{F. GRIFFITH}

F. The strains $M 70,69,71,79,76,75,78,90,85$ and 84 were obtained from a localised outbreak of cerebro-spinal fever at a camp ${ }^{1}$. Seven belonged to Group I, showing every degree of absorptive capacity previously demonstrated; two absorbed agglutinin from the same Group II serum; one absorbed agglutinin partially from a Group I serum and completely from a Group II serum.

${ }^{1}$ In respect of the termination of the disease in these cases Dr Whitley kindly gave me the following information:

Of the 7 infected with Group I strains, 5 died and 1 recovered; in 1 the disease has become chronic and the result is yet in doubt.

Of the 3 infected with Group II strains 1 died and 2 recovered; strains with identical serological characters produced in one case a mild disease and in another a fulminating type. 


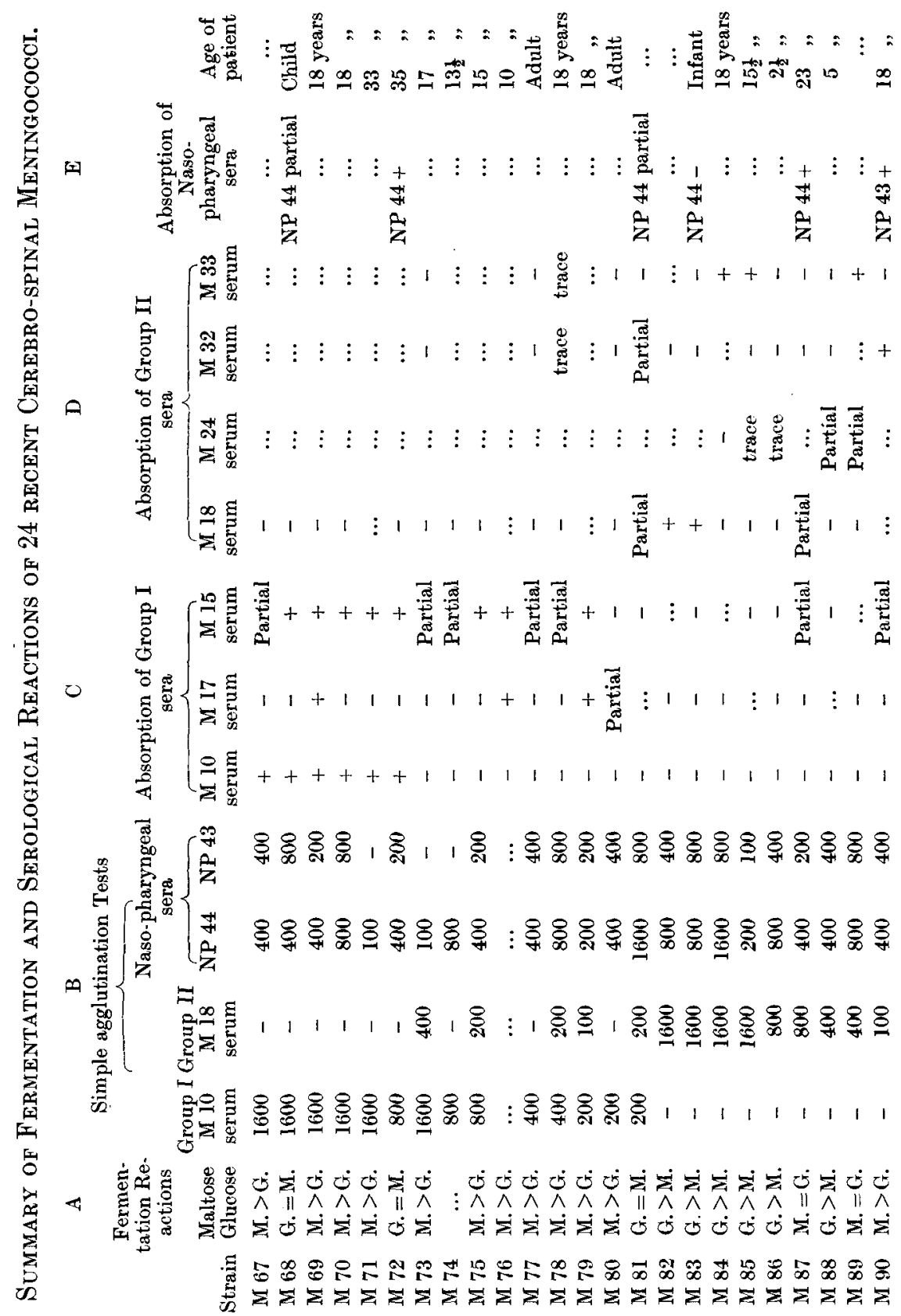

